\title{
Natural Convection Heat Transfer in a Porous Cavity with Sinusoidal Temperature Distribution Using Cu/Water Nanofluid: Double MRT Lattice Boltzmann Method
}

\author{
Hasan Sajjadi ${ }^{1, *}$, Amin Amiri Delouei ${ }^{1}$, Rasul Mohebbi ${ }^{2}$, \\ Mohsen Izadi ${ }^{3}$ and Sauro Succi ${ }^{4,5}$ \\ ${ }^{1}$ Department of Mechanical Engineering, Faculty of Engineering, University of \\ Bojnord, Bojnord, Iran. \\ ${ }^{2}$ School of Engineering, Damghan University, Damghan, Iran. \\ ${ }^{3}$ Mechanical Engineering Department, Faculty of Engineering, Lorestan University, \\ Khorramabad, Iran. \\ ${ }^{4}$ Center for Life Nanoscience, Italian Institute of Technology, Viale Regina Margherita \\ 295, 00161, Roma, Italy. \\ 5 Physics Department, Harvard University, 29 Oxford Street, Cambridge, MA 02138, \\ USA.
}

Received 1 January 2020; Accepted (in revised version) 16 May 2020

\begin{abstract}
In this study, natural convection flow in a porous cavity with sinusoidal temperature distribution has been analyzed by a new double multi relaxation time (MRT) Lattice Boltzmann method (LBM). We consider a copper/water nanofluid filling a porous cavity. For simulating the temperature and flow fields, D2Q5 and D2Q9 lattices are utilized respectively, and the effects of different Darcy numbers (Da) (0.0010.1 ) and various Rayleigh numbers $(\mathrm{Ra})\left(10^{3}-10^{5}\right)$ for porosity $(\varepsilon)$ between 0.4 and 0.9 have been considered. Phase deviation $(\theta)$ changed from 0 to $\pi$ and the volume fraction of nanoparticles $(\varnothing)$ varied from 0 to $6 \%$. The present results show a good agreement with the previous works, thus confirming the reliability the new numerical method proposed in this paper. It is indicated that the heat transfer rate increases at increasing Darcy number, porosity, Rayleigh number, the volume fraction of nanoparticles and phase deviation. However, the most sensitive parameter is the Rayleigh number. The maximum Nusselt deviation is $10 \%, 32 \%$ and $33 \%$ for $\mathrm{Ra}=10^{3}, 10^{4}$ and $10^{5}$, respectively, with $\varepsilon=0.4$ to $\varepsilon=0.9$. It can be concluded that the effect of Darcy number on the heat transfer rate increases at increasing Rayleigh number, yielding a maximum enhancement of the average Nusselt number around $12 \%$ and $61 \%$ for $\mathrm{Ra}=10^{3}$ and $\mathrm{Ra}=10^{5}$, respectively.
\end{abstract}

${ }^{*}$ Corresponding author. Email addresses: Hsajjadi@clarkson.edu (H. Sajjadi), a.a.delouei@gmail.com (A. Amiri Delouei), rasul_mohebbi@du.ac.ir (R. Mohebbi), izadi.m@lu.ac.ir (M. Izadi), succi@iac.cnr.it (S. Succi) 
AMS subject classifications: (or PACs) To be provided by authors

Key words: Porous media, double multi relaxation time-lattice Boltzmann method, nanofluid, natural convection, sinusoidal temperature distribution.

\section{Nomenclature}

$f_{i} \quad$ Distribution function for velocity field

$h_{i} \quad$ Distribution function for temperature field

$\beta \quad$ Thermal expansion coefficient

$\alpha \quad$ Thermal diffusivity

$\rho \quad$ Density

$U \quad$ Velocity in $x$-direction

$V \quad$ Velocity in $y$-direction

$\varepsilon \quad$ Porosity

$v \quad$ Kinematic viscosity

G Gravity

$T$ Temperature

Ra Rayleigh number

$\mu \quad$ Dynamic viscosity

$C_{p}$ Heat capacitance

K Thermal conductivity

\section{Introduction}

In the last decades, the Lattice Boltzmann method (LBM) has developed into a powerful mesoscopic technique to simulate a broad variety of complex flows, such as turbulent flows, flows in porous media, nanofluids, and many others [1-14].

The LBM is consisting of two main steps: collision and streaming, and various models are used to perform the collision step, the simplest and most common being the Lattice Bhatnagar-Gross-Krook (LBGK) [15-26]. Single relaxation time (SRT) has been utilized for the LBGK model, but researchers reported that the LBGK may suffer instability when applied to flows with energy conservation [27]. Ginzburg [29] concluded that tworelaxation-time (TRT) is a suitable model for collision step and this model can overcome the disadvantage of the SRT model. Chikatamarla et al. [29] investigated the Entropic Lattice Boltzmann Model for collision step and reported that the new model is stable and guarantees the thermodynamic consistency of the problem. Also, a comprehensive study on the models which are used for collision step has been down by Luo et al. [30]. They 
compared the various models named multiple-relaxation-time (MRT), TRT, SRT, and the entropic lattice Boltzmann equation (ELBE) and concluded that the MRT model is better than ELBE and LBGK models regarding accuracy, stability, and computational efficiency. Recently Sajjadi et al. [31] applied a new double MRT LBM to solve MHD natural convection in three-dimensional geometry. They used the MRT model for both momentum and energy equations and showed that the new model captured the results well.

Low thermal conductivity of pure fluids which are used for various goals such as: heat exchangers, air-conditioners, solar water heater, etc. motivated research to improve the thermal properties of fluids and it is found that adding even a small amount of nanoparticles to the pure liquids would lead to a substantial increase of the thermal conductivity [32-39]. Numerical simulation of natural convection of $\mathrm{Cu}$ /water nanofluid in a cavity with a sinusoidal wall has been considered by Sheikholeslami et al. [40]. They showed that the heat transfer rate increases by adding nanoparticles to pure fluid, and also enhancing the amplitude of the sinusoidal wall would augment the average Nusselt number. Effects of nanoparticle and phase deviation on heat transfer in a twodimensional enclosure with two sinusoidal wavy walls have been investigated by Tang et al. [41]. Their results showed that the enhancement of the volume fraction of nanoparticles increases the average Nusselt number and by changing the phase deviation, heat transfer rate varied significantly. LBM mesoscopic simulation of three-dimensional natural convection of nanofluid has been performed by Sheikholeslami and Ellahi [42]. These authors concluded that the Nusselt number increases when the Rayleigh number and nanofluid volume fraction are increased. Alsabery et al. [43] used the finite difference method to solve the natural convection of the nanofluid in a two-dimensional cavity. They considered different nanoparticles such as: $\mathrm{Ag}, \mathrm{Cu}, \mathrm{Al} 2 \mathrm{O} 3$, and $\mathrm{TiO} 2$ and reported that the average Nusselt number is considerably enhanced by increasing the solid wall thickness. Mohebbi et al. [44] investigated the effect of a new nanofluid (MWCNT$\mathrm{Fe}_{3} \mathrm{O}_{4}$ /water hybrid nanofluid) on the heat transfer in a channel. Their results showed that heat transfer rate increases by adding the nanoparticles for all cases.

Flow in porous media is essential in various applications such as: geothermal reservoirs, heat exchangers, prevention of subsoil water pollution, etc. [45-47]. Numerical simulation of convective heat transfer in a porous media have been investigated by various methods [48,49], one of the techniques that has been receiving increasing attention for transport in porous media is LBM $[50,51]$, due its simplicity in dealing with grossly irregular geometries.

This method can be used in porous media with two main scales: the first one is the pore scale method and the second one is the representative elementary volume (REV) [51-53]. For the REV scale, various models such as: Darcy model, the Brinkman-extended Darcy model, the Forchheimer-extended Darcy model and Brinkman-Forchheimerextended Darcy model are used to add an extra term to the standard LB equation to consider the effect of porous media [52,54]. Guo and Zhao [55] concluded that the BrinkmanForchheimer-extended Darcy model, named "generalized model", overcomes some limitations of the Darcy model, Brinkman-extended Darcy model, and Forchheimer-extended 
Darcy model. Kefayati [56] used Finite Difference Lattice Boltzmann method (FDLBM) to investigate natural convection of nanofluid in a porous cavity: this author applied the REV scale and showed that this method recovers the correct results. Ashorynejad and Hoseinpour [57] investigated the effect of porosity on entropy generation and reported that the augmentation of porosity enhances the total entropy generation, because of enhancement in fluid friction.

The double MRT LBM is known as a recent method to solve the flows numerically, and needs more work to develop in complex flow with various boundary conditions. The primary aim of this study is to use the double MRT LBM to investigate the natural convection of nanofluid in a porous cavity with a sinusoidal temperature distribution on the boundary conditions as a complex one. The REV scale with the generalized model is used to consider the effect of porous media and D2Q5, and D2Q9 lattices are applied to simulate the temperature and flow fields respectively. Also, it is endeavored to capture the impact of various parameters $(\mathrm{Ra}, \mathrm{Da}, \varepsilon, \theta, \varnothing)$ on the heat transfer rate.

\section{Problem statement}

The two-dimensional square cavity considered in this study, is shown in Fig. 1. The temperature of the left side is set at a constant value $T_{h}$, while the right side obeys a sinusoidal law $T=T_{0}+A \sin \left(\frac{2 \pi y}{L}+\theta\right)$, while the top and bottom walls are adiabatic. All four walls are fixed and non-slip boundary condition is used for them. The porous cavity is filled with $\mathrm{Cu}$ /water nanofluid assumed as a Newtonian and incompressible fluid. Also, the flow is laminar, and viscous heat dissipation is negligible. At the REV scale and based on the generalized model the dimensional equations can be written as [54]:

$$
\begin{aligned}
& \frac{\partial U}{\partial X}+\frac{\partial V}{\partial Y}=0, \\
& \frac{\partial U}{\partial t}+\frac{U}{\varepsilon} \frac{\partial U}{\partial X}+\frac{V}{\varepsilon} \frac{\partial U}{\partial Y}=-\frac{\varepsilon}{\rho} \frac{\partial P}{\partial X}+v\left(\frac{\partial^{2} U}{\partial X^{2}}+\frac{\partial^{2} U}{\partial Y^{2}}\right)+F_{x} \\
& \frac{\partial V}{\partial t}+\frac{U}{\varepsilon} \frac{\partial V}{\partial X}+\frac{V}{\varepsilon} \frac{\partial V}{\partial Y}=-\frac{\varepsilon}{\rho} \frac{\partial P}{\partial Y}+v\left(\frac{\partial^{2} V}{\partial X^{2}}+\frac{\partial^{2} V}{\partial Y^{2}}\right)+F_{y} \\
& \sigma \frac{\partial T}{\partial t}+U \frac{\partial T}{\partial X}+V \frac{\partial T}{\partial Y}=\alpha\left(\frac{\partial^{2} T}{\partial X^{2}}+\frac{\partial^{2} T}{\partial Y^{2}}\right)
\end{aligned}
$$

where $\sigma=\rho C_{p}, F_{x}$ and $F_{y}$ calculated as [52]

$$
\begin{aligned}
& F_{x}=-\frac{\varepsilon V}{K} U-\frac{\varepsilon F_{\varepsilon}}{\sqrt{K}} U \sqrt{|U|^{2}+|V|^{2}}, \\
& F_{y}=-\frac{\varepsilon V}{K} V-\frac{\varepsilon F_{\varepsilon}}{\sqrt{K}} V \sqrt{|U|^{2}+|V|^{2}}+\varepsilon\left(g \beta\left(T-T_{r e f}\right)\right) .
\end{aligned}
$$




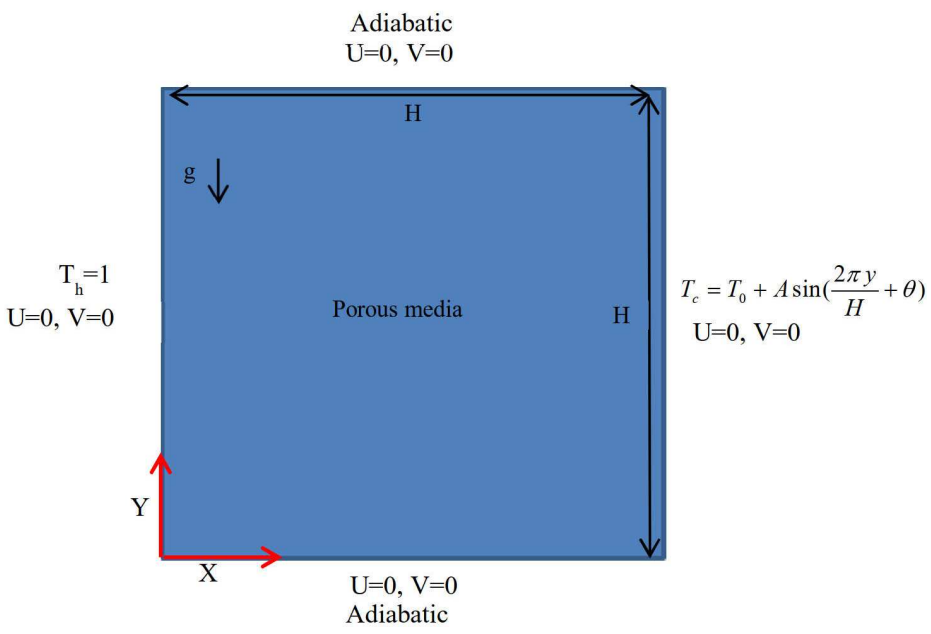

Figure 1: The geometry of the present study.

In Eqs. (2.5) and (2.6), $K$ is permeability and $F_{\varepsilon}$ obtained as [52]:

$$
F_{\varepsilon}=\frac{1.75}{\sqrt{150 \varepsilon^{3}}} .
$$

\section{MRT Lattice Boltzmann method for flow field}

In the present study for flow field, lattice Boltzmann method with MRT model is used, and D2Q9 lattice (Fig. 2) is utilized to evaluate the distribution functions for velocity as [52]:

$$
f_{i}\left(x+c_{i} \Delta t, t+\Delta t\right)=f_{i}(x, t)-M_{i j}{ }^{-1} \cdot S_{j k} \cdot\left[m_{k}(x, t)-m_{k}^{e q}(x, t)\right]+M_{i j}{ }^{-1} \Delta t\left[I-\frac{S_{j k}}{2}\right] R .
$$

In Eq. (3.1) $f_{i}$ is the velocity distribution function, $\Delta t$ denotes the lattice time step that was set to unity. $c_{i}$ is the discrete fluid particle velocity vector for D2Q9 model that is defined in Fig. 2 and is reported as [34]:

$$
c_{i}= \begin{cases}0, & i=0, \\ c( \pm 1,0), & i=1,3, \\ c(0, \pm 1), & i=2,4 \\ c( \pm 1, \pm 1), & i=5,6,7,8\end{cases}
$$

where $c$ is the lattice speed and equals to $\Delta x / \Delta t$ which also set equal to unity. $M_{i j}$ is the transformation matrix, $S_{j k}$ is the diagonal matrix of relaxation rates for momentum 


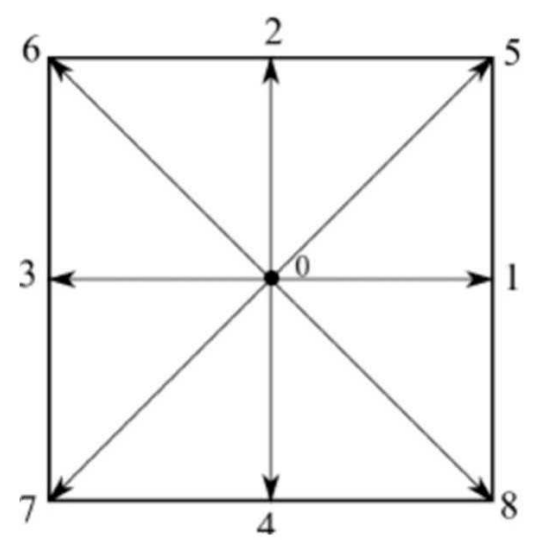

Figure 2: The discrete velocity vectors for D2Q9.

distribution and they can be calculated as follow for D2Q9 [52]:

$$
\begin{aligned}
M & =\left(\begin{array}{ccccccccc}
1 & 1 & 1 & 1 & 1 & 1 & 1 & 1 & 1 \\
-4 & -1 & -1 & -1 & -1 & 2 & 2 & 2 & 2 \\
4 & -2 & -2 & -2 & -2 & 1 & 1 & 1 & 1 \\
0 & 1 & 0 & -1 & 0 & 1 & -1 & -1 & 1 \\
0 & -2 & 0 & 2 & 0 & 1 & -1 & -1 & 1 \\
0 & 0 & 1 & 0 & -1 & 1 & 1 & -1 & -1 \\
0 & 0 & -2 & 0 & 2 & 1 & 1 & -1 & -1 \\
0 & 1 & -1 & 1 & -1 & 0 & 0 & 0 & 0 \\
0 & 0 & 0 & 0 & 0 & 1 & -1 & 1 & -1
\end{array}\right), \\
S_{i j} & =\operatorname{diag}\left(s_{0}, s_{1}, \cdots, s_{8}\right),
\end{aligned}
$$

where $s_{0}, s_{1}, \cdots, s_{8}$ are the relaxation times in various directions which are as the following value for this study:

$$
s_{0,3,5}=1, \quad s_{7,8}=\frac{1}{\tau_{v}}, \quad s_{1,2}=1.1, \quad s_{4,6}=1.2 .
$$

Here $\tau_{v}=3 v+0.5$ and to evaluate the velocity moments $\left(m_{k}\right)$ in Eq. (3.1) we have:

$$
m=M f .
$$

Also, the equilibrium moments $\left(m_{k}^{e q}\right)$ for the velocity moments $m_{k}$ in Eq. (3.1) can be obtained as:

$$
m^{e q}=\left(\rho,-2 \rho+\frac{3 \rho|u|^{2}}{\varepsilon}, \rho-\frac{3 \rho|u|^{2}}{\varepsilon}, \rho U,-\rho U, \rho V,-\rho V, \frac{\rho\left(U^{2}-V^{2}\right)}{\varepsilon}, \frac{\rho U V}{\varepsilon}\right) .
$$


In Eq. (3.1), $I$ is the unit matrix and finally, $R$ is the force term in the moment space and is given as [52]:

$$
\begin{aligned}
& R_{0}=0, \quad R_{1}=\frac{6 \rho\left(U F_{x}+V F_{y}\right)}{\varepsilon}, \\
& R_{2}=-\frac{6 \rho\left(U F_{x}+V F_{y}\right)}{\varepsilon}, \quad R_{3}=\rho F_{x}, \\
& R_{4}=-\rho F_{x}, \quad R_{5}=\rho F_{y}, \quad R_{6}=-\rho F_{y}, \\
& R_{7}=\frac{2 \rho\left(U F_{x}-V F_{y}\right)}{\varepsilon}, \quad R_{8}=\frac{\rho\left(U F_{y}+V F_{x}\right)}{\varepsilon} .
\end{aligned}
$$

\section{MRT Lattice Boltzmann method for temperature field}

In this paper, the MRT Lattice Boltzmann method is used for solving both the fluid equation and the temperature dynamics. For the latter, the D2Q5 lattice (Fig. 3) is utilized as [31]:

$$
h_{i}\left(x+e_{i} \Delta t, t+\Delta t\right)=h_{i}(x, t)-N_{i j}^{-1} \cdot Q_{j k} \cdot\left[n_{k}(x, t)-n_{k}^{e q}(x, t)\right] .
$$

Here $h_{i}$ is the distribution function for the temperature and $e_{i}$ is the discrete fluid particle velocity vector for D2Q5 (Fig. 3) and is defined as:

$$
e_{i}= \begin{cases}0, & i=0, \\ c( \pm 1,0), & i=1,3, \\ c(0, \pm 1), & i=2,4 .\end{cases}
$$

In Eq. (4.1) $N_{i j}$ is the transformation matrix, $Q_{i j}$ is the diagonal matrix of relaxation rates and can be obtained by [52]:

$$
\begin{aligned}
N & =\left(\begin{array}{ccccc}
1 & 1 & 1 & 1 & 1 \\
0 & 1 & 0 & -1 & 0 \\
0 & 0 & 1 & 0 & -1 \\
-4 & 1 & 1 & 1 & 1 \\
0 & 1 & -1 & 1 & -1
\end{array}\right), \\
Q_{i j} & =\operatorname{diag}\left(q_{0}, q_{1}, \cdots, q_{4}\right) .
\end{aligned}
$$

Components of the matrix of relaxation time for the present study are defined as:

$$
q_{0}=1, \quad q_{1,2}=\frac{1}{\tau_{T}}, \quad q_{3,4}=1.5,
$$

where $\tau_{T}=5 \alpha+0.5$. The velocity moments of $h_{i}\left(n_{k}\right)$ calculated as:

$$
n=N h \text {. }
$$




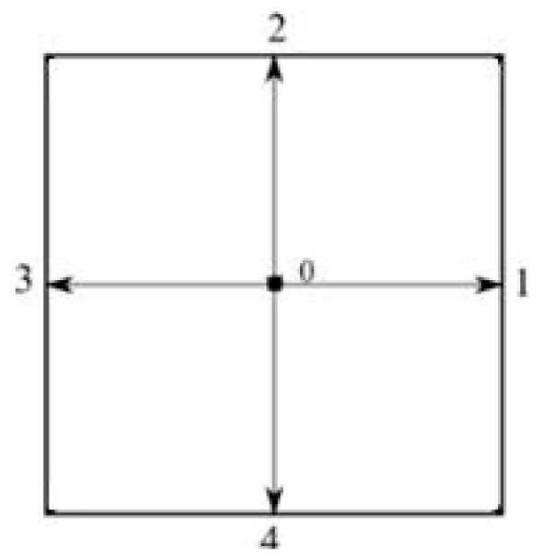

Figure 3: The discrete velocity vectors for D2Q5.

Finally, the equilibrium moments $\left(n_{k}^{e q}\right)$ of the velocity moments of $h_{i}$ for the present geometry is given as:

$$
n^{e q}=\left(T, \frac{U T}{\sigma}, \frac{V T}{\sigma},-2 T, 0\right) .
$$

After obtaining the velocity and temperature distribution functions $\left(f_{i}\right.$ and $\left.h_{i}\right)$ in all directions, the macroscopic quantities $(u$ and $T)$ are given as:

$$
u=\frac{W}{a_{0}+\sqrt{a_{0}^{2}+a_{1}|W|}},
$$

where $a_{0}, a_{1}$ and $W$ are calculated as:

$$
\begin{aligned}
& a_{0}=0.5\left(1+\frac{\varepsilon v}{2 k}\right), \\
& a_{1}=\frac{\varepsilon F_{\varepsilon}}{2 \sqrt{k}} \\
& W=\sum_{0}^{8} c_{i} f_{i} / \rho+\operatorname{cg} \beta \Delta T / 2, \\
& T=\sum_{0}^{4} h_{i} .
\end{aligned}
$$

\section{Lattice Boltzmann method for nanofluid}

For natural convection flow, Rayleigh number is one of the most important parameters and is given as: 
Table 1: Thermophysical properties of water and copper [31].

\begin{tabular}{||ccc||}
\hline Property & $\mathrm{Cu}$ & Water \\
\hline Viscosity $(\mu)(\mathrm{kg} / \mathrm{ms})$ & - & $8 \times 10^{-4}$ \\
Specific heat capacity $\left(C_{p}\right)(j / \mathrm{kg} k)$ & 383 & 4179 \\
Density $(\rho)\left(\mathrm{kg} / \mathrm{m}^{3}\right)$ & 8954 & 997 \\
Thermal expansion coefficient $(\beta)\left(k^{-1}\right)$ & $1.67 \times 10^{-5}$ & $2.1 \times 10^{-4}$ \\
Thermal conductivity $(k)(w / \mathrm{m} k)$ & 400 & 0.6 \\
\hline
\end{tabular}

$$
\mathrm{Ra}=\frac{\beta g H^{3} \operatorname{Pr}\left(T_{H}-T_{C}\right)}{v^{2}}
$$

where $\beta$ is the thermal expansion coefficient (equals to $1 / T$, for ideal gases, where $T$ is absolute temperature), $g$ is acceleration due to gravity, $v$ is the kinematic viscosity, Pr is the Prandtl number and $H$ is the cavity length.

In this work, we assume that the nanofluid is similar to the base fluid and nanofluid properties have been computed using the equations and the thermo-physical properties of solid and fluid phases given in Table 1.

To compute the thermal expansion coefficient $(\beta)$ of the nanofluid, the following equation is applied [28]:

$$
(\rho \beta)_{n f}=(1-\phi)(\rho \beta)_{f}+\phi(\rho \beta)_{s} .
$$

The heat capacitance $\left(c_{p}\right)$ and the effective density of the nanofluid are given as [31]:

$$
\begin{aligned}
& \left(\rho c_{p}\right)_{n f}=(1-\phi)\left(\rho c_{p}\right)_{f}+\phi\left(\rho c_{p}\right)_{s^{\prime}} \\
& \rho_{n f}=(1-\varphi) \rho_{f}+\varphi \rho_{s} .
\end{aligned}
$$

Also, the dynamic viscosity of the nanofluid is calculated as [31]:

$$
\mu_{n f}=\frac{\mu_{f}}{(1-\phi)^{2.5}}
$$

To evaluate the effective thermal conductivity of the nanofluid, the Maxwell-Garnetts (MG) model is utilized [31]:

$$
\frac{k_{n f}}{k_{f}}=\frac{k_{s}+2 k_{f}-2 \phi\left(k_{f}-k_{s}\right)}{k_{s}+2 k_{f}+\phi\left(k_{f}-k_{s}\right)},
$$

where in Eqs. (5.2)-(5.6), $\phi$ is the volume fraction of the solid particles and subscripts $s$, $n f$ and $f$ are used for solid, nanofluid and base fluid, respectively. 


\section{Code validation and grid independence}

In this paper, the average and local Nusselt numbers are calculated as:

$$
\begin{aligned}
& N u_{\text {Local }}=\left.\frac{H}{\Delta T} \frac{-\partial T}{\partial x}\right|_{x=0, L^{\prime}}, \\
& N u_{\text {avg }}=\int_{0}^{H} N u_{\text {local }} d y .
\end{aligned}
$$

An extensive mesh testing procedure was conducted to guarantee the independence of solution of grid sizes. The average Nusselt number on the hot wall at $\mathrm{Ra}=10^{3}, \mathrm{Da}=$ $10^{-2}, \varepsilon=0.4$ and $\theta=0$ for the base fluid, were calculated over a range of grid resolutions and shown in the Table 2. As the results show, the average Nusselt number did not change significantly when grid resolutions increase from M3 to M4, so a $(140 \times 140)$ grid resolution was chosen.

Table 2: Grid independence study.

\begin{tabular}{||c|c|c|c|c||}
\hline & M1 & M2 & M3 & M4 \\
\hline Grid & $100 \times 100$ & $120 \times 120$ & $140 \times 140$ & $160 \times 160$ \\
\hline$N u_{\text {avg }}$ & 1.201 & 1.151 & 1.105 & 1.103 \\
\hline
\end{tabular}

Validation with the previous works has been performed in two subjects to ensure the accuracy of the present work. First, the solution for nanofluid is validated against the work of Khanafer et al. [58] in Fig. 4. As it is seen in Fig. 4, the present method captures the results for the nanofluid within a maximum error less than $5 \%$.

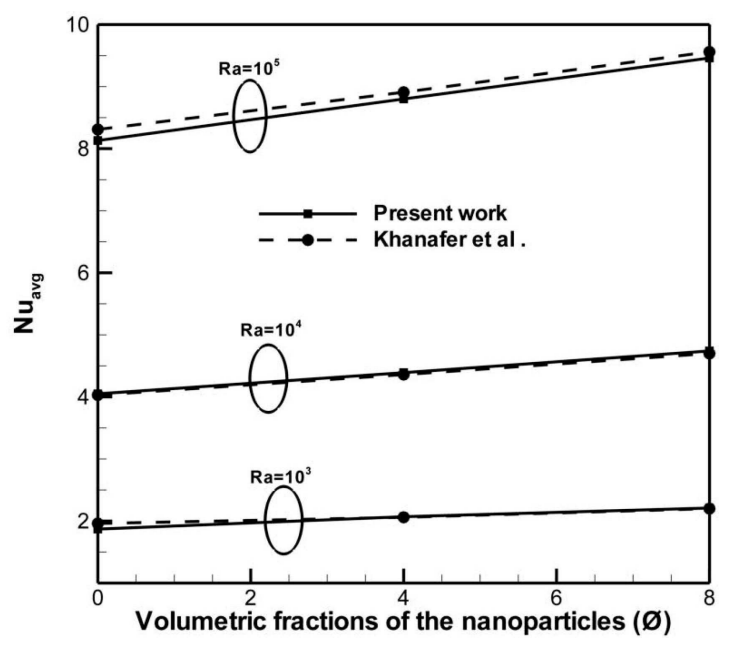

Figure 4: Comparison of the average Nusselt number for various volumetric fractions of the nanoparticles with the previous work [58]. 


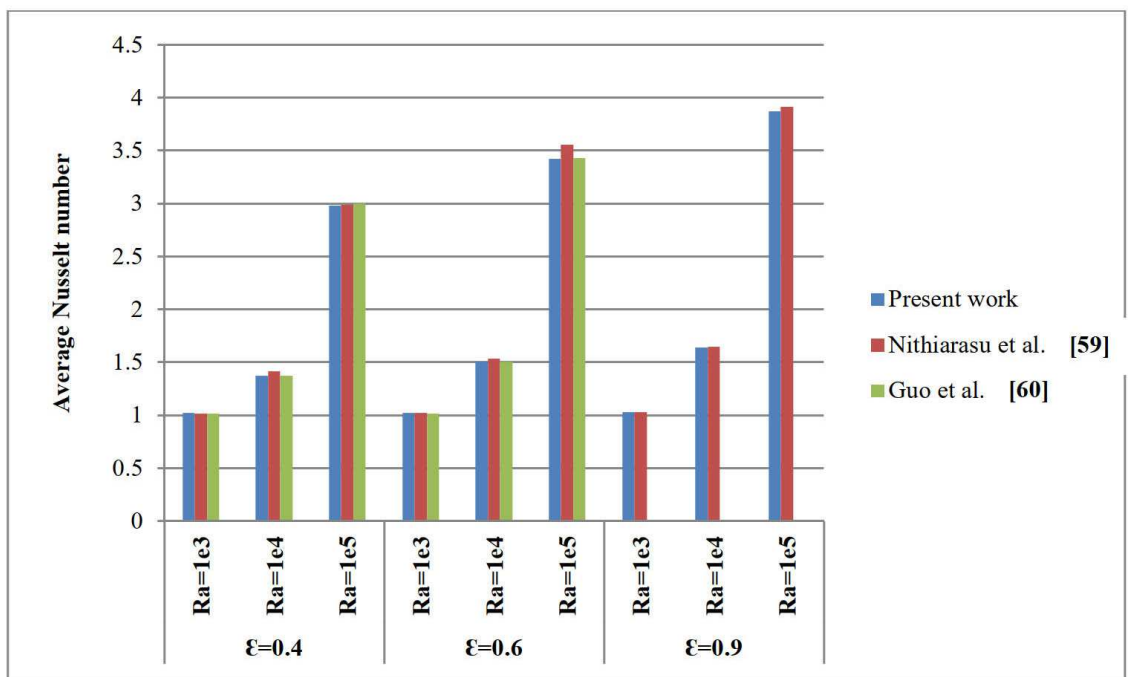

(a)

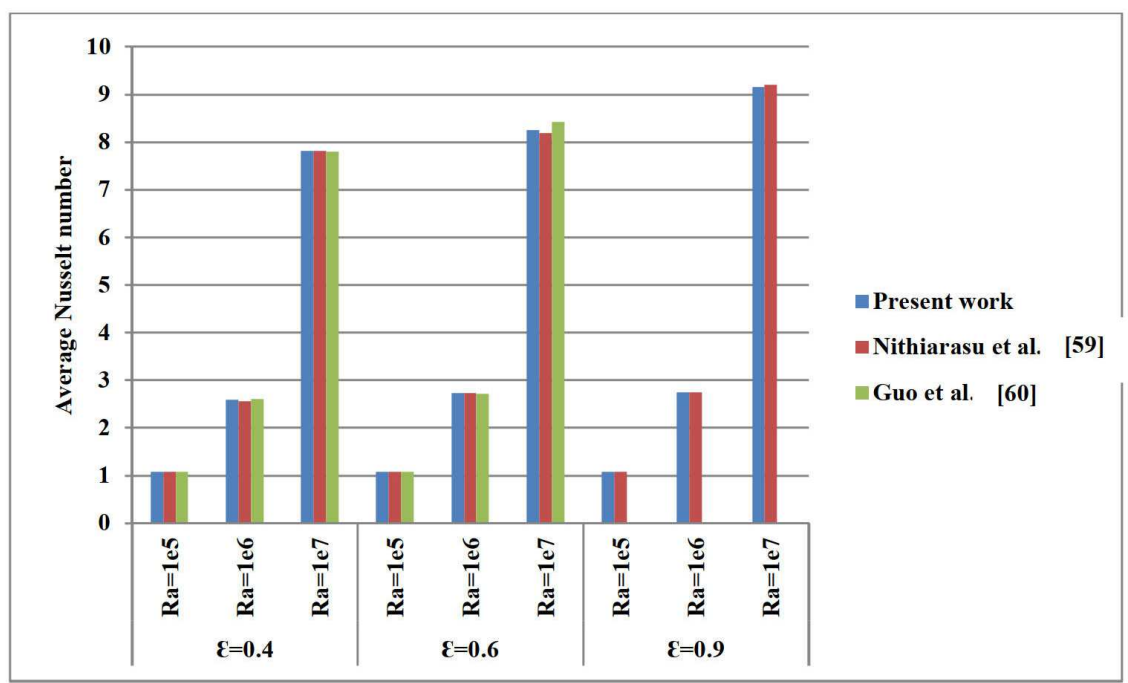

(b)

Figure 5: Comparison of the average Nusselt number for various Darcy numbers and porosities with the previous works $[59,60]$. (a) $\mathrm{Da}=10^{-2}$; (b) $\mathrm{Da}=10^{-4}$.

The second validation was performed for natural convection in a porous media, and the present results are validated against the work of Nithiarasu et al. [59] and Guo et al. [60] in Fig. 5. The results show a good agreement with the previous work, with a maximum error around $4 \%$. We conclude that the present method is suitable for flows in porous media well. 


\section{Results and discussion}

In this study, the effect of various parameters such as Rayleigh number, Darcy number, porosity, phase deviation and volumetric fraction of the nanoparticles on the heat transfer and flow field of the nanofluid in the porous cavity have been discussed. Figs. 6-11 illustrate the temperature contours and streamlines for various parameters at $\varnothing=0$. It is observed that the isotherms and streamlines change significantly with the porosity. Since porosity is directly associated with the permeability of porous medium, by increasing the porosity, isotherms spread across the porous cavity, thereby approaching the walls. Therefore, the convection process is becoming stronger with increasing the porosity, for all Rayleigh numbers, Darcy numbers, and phase deviations. Also, the streamlines confirm the above picture in isotherms as the enhancement in porosity concludes in the ex-
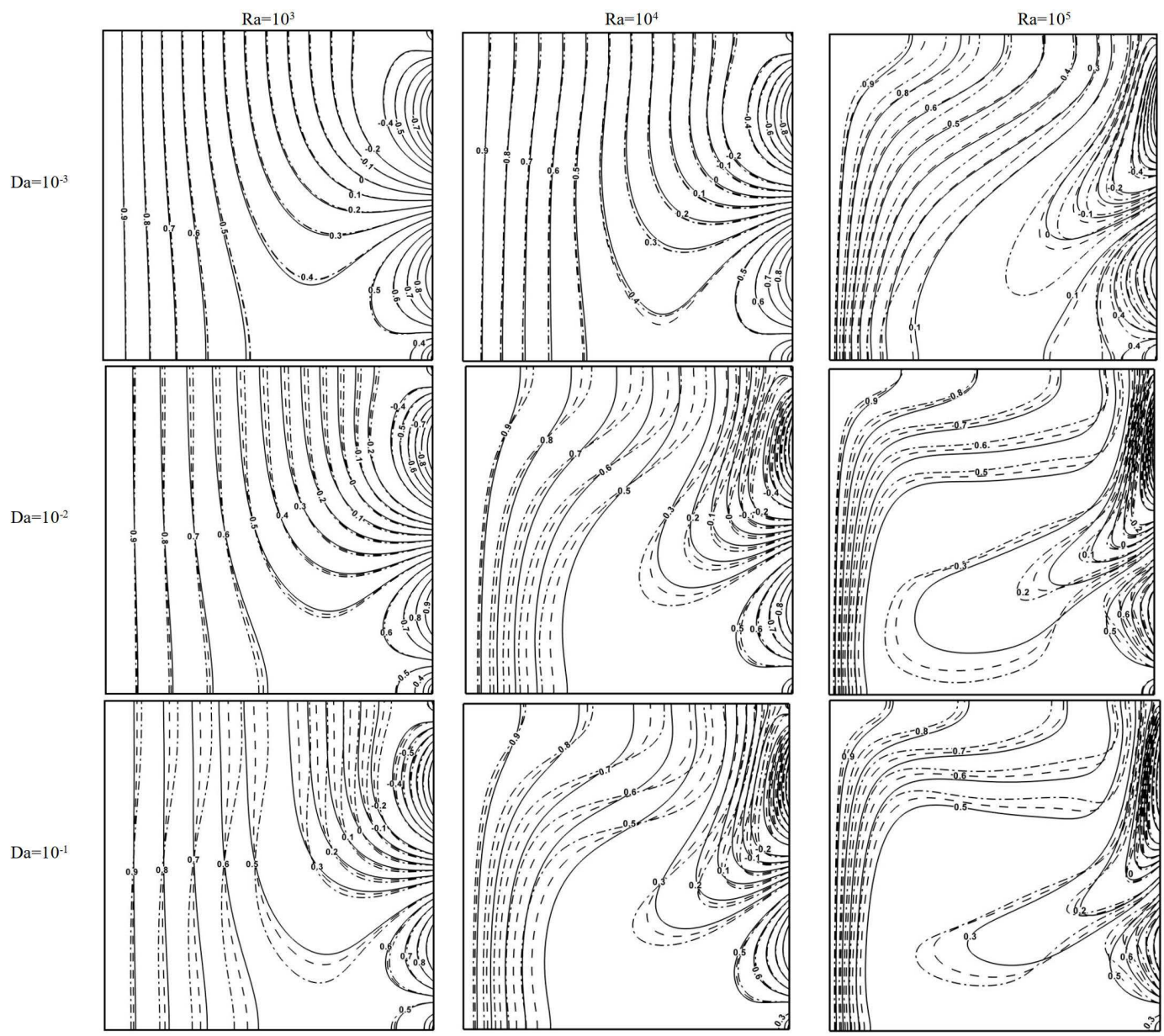

Figure 6: Temperature contours for $\theta=0, \varnothing=0$, various Darcy and Rayleigh numbers and different porosities $\varepsilon=0.4$ (solid), $\varepsilon=0.6$ (dashed), $\varepsilon=0.9$ (dashed-dot). 

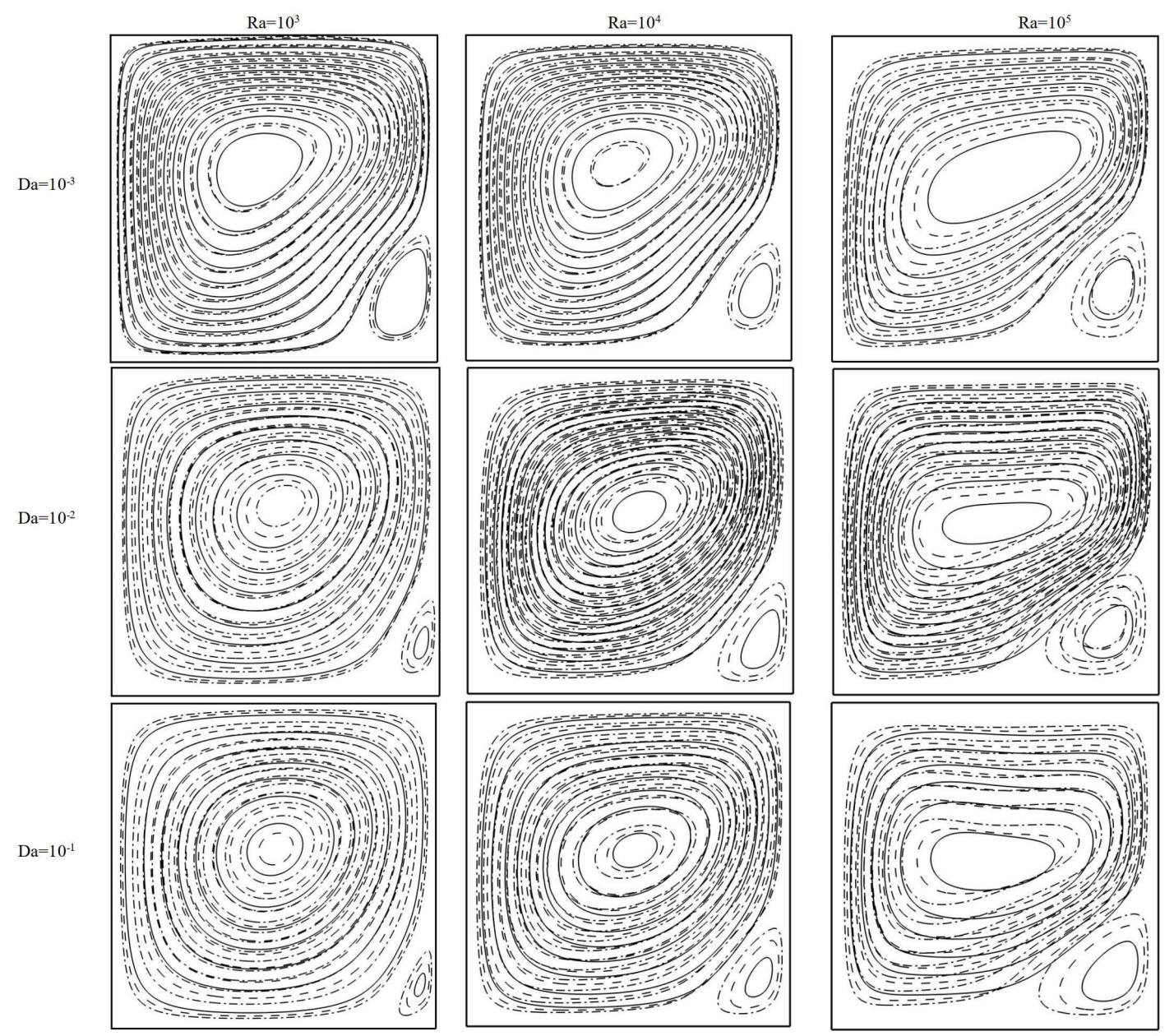

Figure 7: Streamlines for $\theta=0, \varnothing=0$, various Darcy and Rayleigh numbers and different porosities $\varepsilon=0.4$ (solid), $\varepsilon=0.6$ (dashed), $\varepsilon=0.9$ (dashed-dot).

pansion of the streamlines and improving the maximum stream functions. The effect of the porosity on the heat and flow field increases by enhancing of Darcy number and Rayleigh number, with the most intense effect observed at $\mathrm{Da}=10^{-1}$ and $\mathrm{Ra}=10^{5}$ (Figs. 611). Enhancing the Darcy number and Rayleigh number also affects the flow pattern, as the higher Darcy and Rayleigh number reinforce convective motion and thermal conductance, that results in a enhanced heat transfer rate (Figs. 6-11). In addition, the Rayleigh number has the greatest effect on the flow pattern in comparison with porosity and Darcy number.

The effects of porosity, Rayleigh number and Darcy number on the local Nusselt number are shown in Fig. 12 for the right wall. It is evident that the enhancement of porosity slightly increases the peaks of the local Nusselt number for all Darcy and Rayleigh numbers, which means an increase of the heat transfer rate. Also, the effect of porosity 

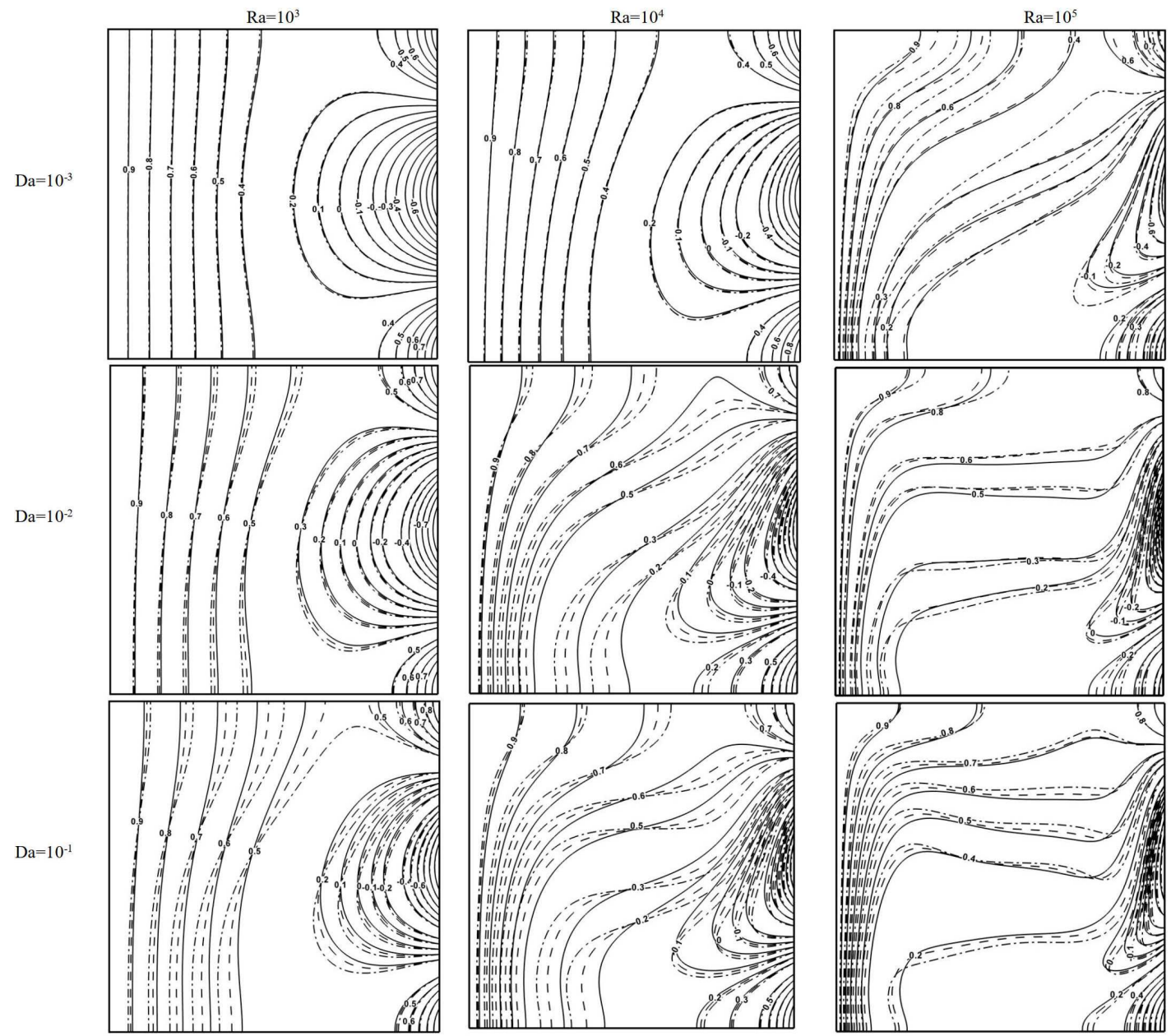

Figure 8: Temperature contours for $\theta=\pi / 2, \varnothing=0$, various Darcy and Rayleigh numbers and different porosities $\varepsilon=0.4$ (solid), $\varepsilon=0.6$ (dashed), $\varepsilon=0.9$ (dashed-dot).

augments with Rayleigh number, as the augmentation of positive peak is $1 \%, 20 \%$ and $22 \%$ for $\mathrm{Da}=10^{-2}$ and $\mathrm{Ra}=10^{3}, 10^{4}$ and $10^{5}$, respectively, when the porosity increases from 0.4 to 0.9 which is important for designing the solar heating system and geothermal reservoirs. In addition, changing the Rayleigh number results in a significant increase of the local Nusselt number (Fig. 12). Additional, Darcy number positively affect the local Nusselt number, as by enhancement of Darcy number maximum value of the local Nusselt number augments smoothly. Generally, Fig. 12 indicates that the Rayleigh number has the greatest effect on the local Nusselt number, which confirms the results shown in Figs. 8-11.

The average Nusselt number for the left wall is reported in the Tables 3,4 and 5 for $\mathrm{Ra}=10^{3}, 10^{4}$ and $10^{5}$, respectively. Results show that the average Nusselt number in- 

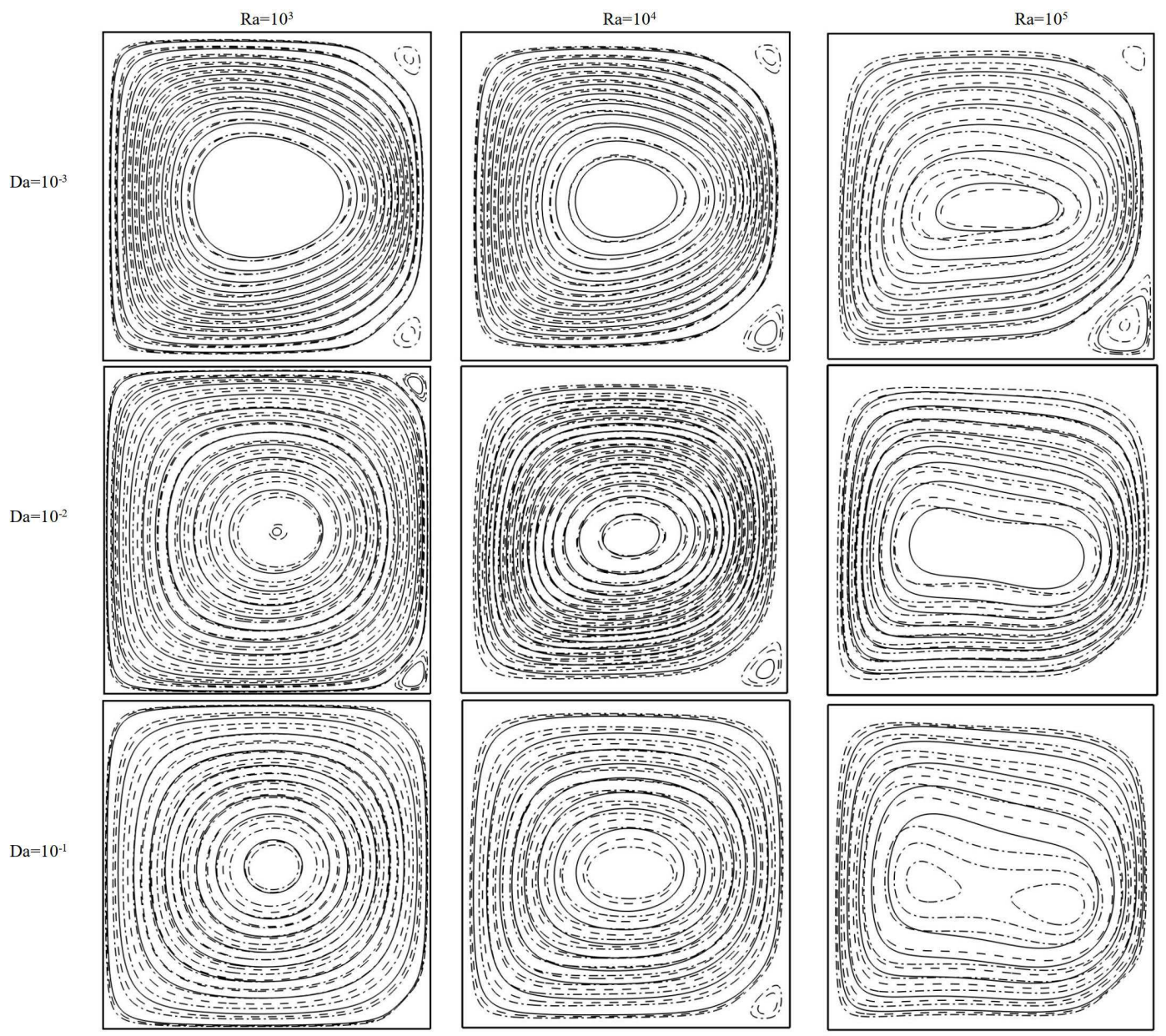

Figure 9: Streamlines for $\theta=\pi / 2, \varnothing=0$, various Darcy and Rayleigh numbers and different porosities $\varepsilon=0.4$ (solid), $\varepsilon=0.6$ (dashed), $\varepsilon=0.9$ (dashed-dot).

Table 3: The average Nusselt number on the left wall for $\operatorname{Ra}=10^{3}$ and $\varnothing=0$.

\begin{tabular}{||c|ccc|ccc|ccc||}
\hline & \multicolumn{3}{|c|}{$\varepsilon=0.4$} & \multicolumn{3}{c||}{$\varepsilon=0.6$} & \multicolumn{3}{c||}{$\varepsilon=0.9$} \\
\hline & $\theta=0$ & $\theta=\pi / 2$ & $\theta=\pi$ & $\theta=0$ & $\theta=\pi / 2$ & $\theta=\pi$ & $\theta=0$ & $\theta=\pi / 2$ & $\theta=\pi$ \\
\hline $\mathrm{Da}=10^{-3}$ & 1.09 & 1.16 & 1.18 & 1.09 & 1.16 & 1.19 & 1.08 & 1.17 & 1.19 \\
$\mathrm{Da}=10^{-2}$ & 1.10 & 1.16 & 1.19 & 1.09 & 1.17 & 1.20 & 1.09 & 1.18 & 1.22 \\
$\mathrm{Da}=10^{-1}$ & 1.11 & 1.18 & 1.22 & 1.10 & 1.21 & 1.27 & 1.09 & 1.27 & 1.34 \\
\hline
\end{tabular}

creases by porosity for all cases, as the maximum Nusselt deviation is $10 \%, 32 \%$ and $33 \%$ for $\mathrm{Ra}=10^{3}, 10^{4}$ and $10^{5}$, respectively, for $\varepsilon=0.4$ to $\varepsilon=0.9$ which is noticeable for designing an optimum system in engineering applications such as building thermal insulation and direct contact heat exchangers. Also, it is seen that the average Nusselt number increases 

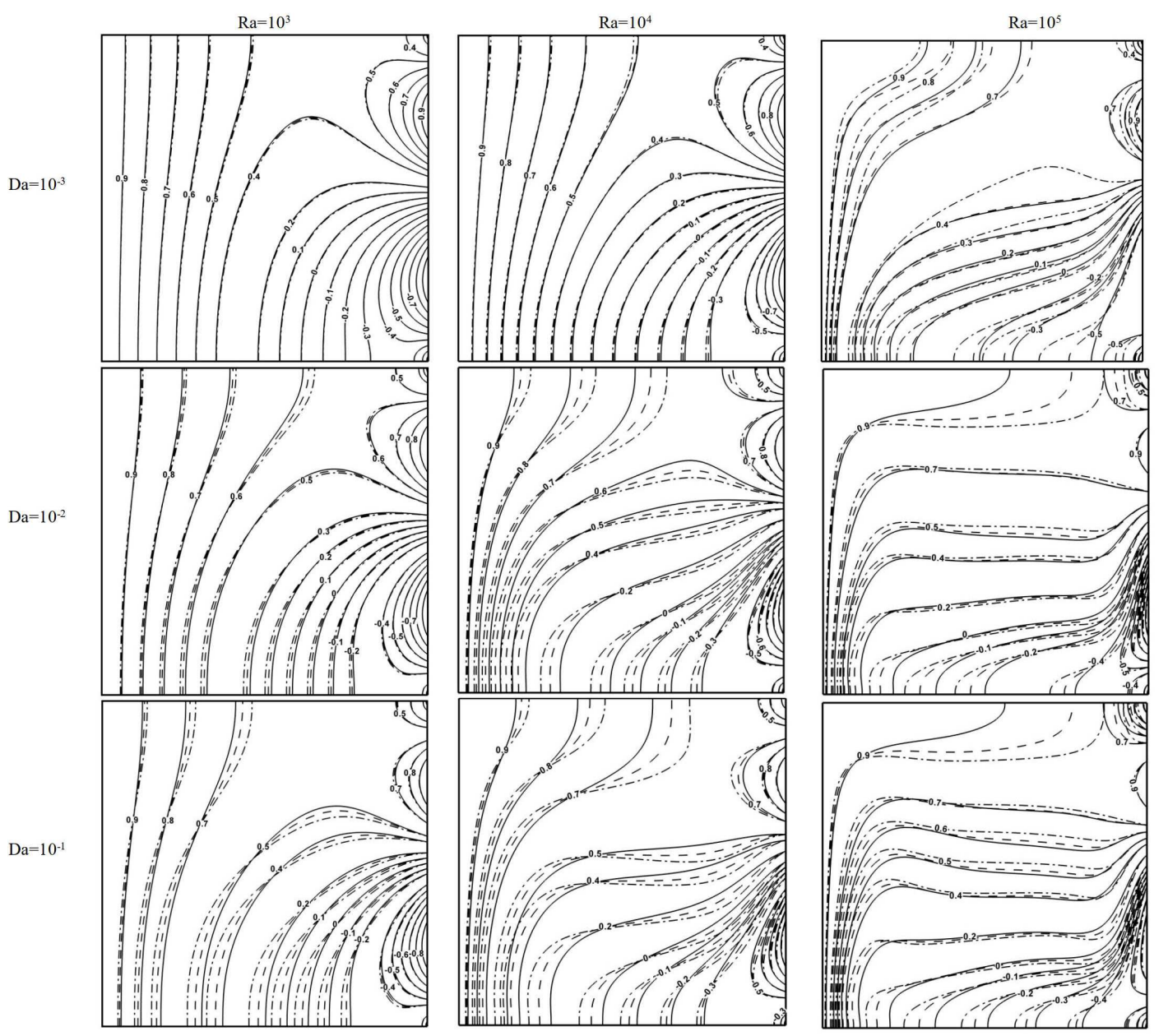

Figure 10: Temperature contours for $\theta=\pi, \varnothing=0$, various Darcy and Rayleigh numbers and different porosities $\varepsilon=0.4$ (solid), $\varepsilon=0.6$ (dashed), $\varepsilon=0.9$ (dashed-dot).

Table 4: The average Nusselt number on the left wall for $\operatorname{Ra}=10^{4}$ and $\varnothing=0$.

\begin{tabular}{||c|ccc|ccc|ccc||}
\hline & \multicolumn{3}{|c|}{$\varepsilon=0.4$} & \multicolumn{3}{c||}{$\varepsilon=0.6$} & \multicolumn{3}{c||}{$\varepsilon=0.9$} \\
\hline & $\theta=0$ & $\theta=\pi / 2$ & $\theta=\pi$ & $\theta=0$ & $\theta=\pi / 2$ & $\theta=\pi$ & $\theta=0$ & $\theta=\pi / 2$ & $\theta=\pi$ \\
\hline $\mathrm{Da}=10^{-3}$ & 1.48 & 1.59 & 1.64 & 1.55 & 1.61 & 1.65 & 1.56 & 1.62 & 1.66 \\
$\mathrm{Da}=10^{-2}$ & 1.49 & 1.83 & 1.88 & 1.62 & 2.00 & 2.04 & 1.78 & 2.17 & 2.20 \\
$\mathrm{Da}=10^{-1}$ & 1.69 & 2.10 & 2.12 & 1.94 & 2.39 & 2.39 & 2.23 & 2.71 & 2.69 \\
\hline
\end{tabular}

considerably with Rayleigh number under all situations, the maximum increase (344\%) occurring at $\mathrm{Da}=10^{-1}, \varepsilon=0.9$, and $\theta=0$, with increasing of Rayleigh number from $10^{3}$ to $10^{5}$. It can be concluded that the effect of Darcy number on the heat transfer rate increases 

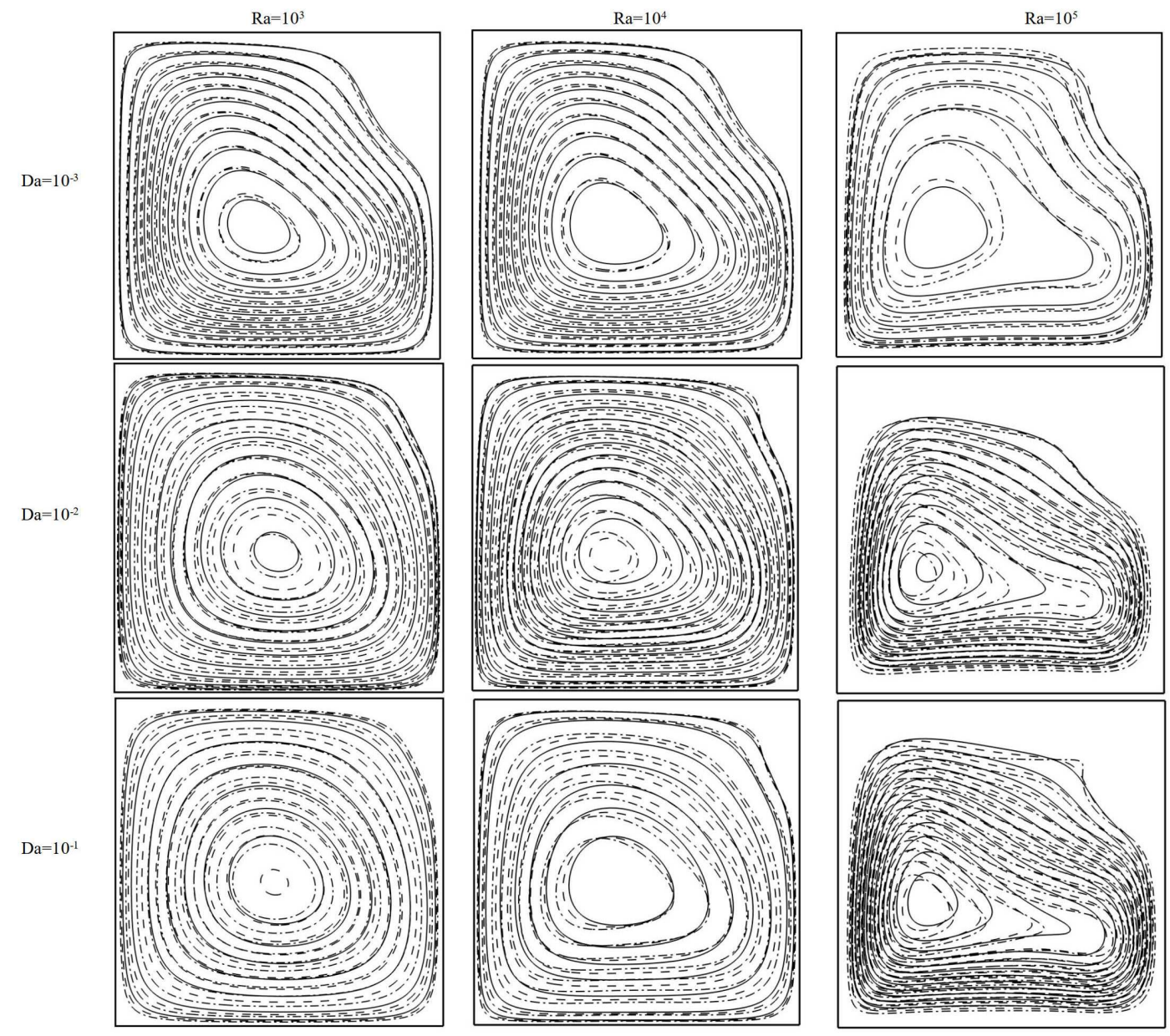

Figure 11: Streamlines for $\theta=\pi, \varnothing=0$, various Darcy and Rayleigh numbers and different porosities $\varepsilon=0.4$ (solid), $\varepsilon=0.6$ (dashed), $\varepsilon=0.9$ (dashed-dot).

Table 5: The average Nusselt number on the left wall for $\mathrm{Ra}=10^{5}$ and $\varnothing=0$.

\begin{tabular}{||c|ccc|ccc|ccc||}
\hline & \multicolumn{3}{|c|}{$\varepsilon=0.4$} & \multicolumn{3}{c||}{$\varepsilon=0.6$} & \multicolumn{3}{c||}{$\varepsilon=0.9$} \\
\hline & $\theta=0$ & $\theta=\pi / 2$ & $\theta=\pi$ & $\theta=0$ & $\theta=\pi / 2$ & $\theta=\pi$ & $\theta=0$ & $\theta=\pi / 2$ & $\theta=\pi$ \\
\hline $\mathrm{Da}=10^{-3}$ & 2.64 & 2.94 & 2.96 & 2.76 & 3.04 & 3.06 & 3.29 & 3.46 & 3.47 \\
$\mathrm{Da}=10^{-2}$ & 3.52 & 4.07 & 4.09 & 4.04 & 4.65 & 4.60 & 4.56 & 5.10 & 5.15 \\
$\mathrm{Da}=10^{-1}$ & 3.66 & 4.30 & 4.35 & 4.23 & 4.87 & 4.95 & 4.84 & 5.48 & 5.61 \\
\hline
\end{tabular}

by augmentation of Rayleigh number, as the maximum enhancement of average Nusselt number is $12 \%$ for $\mathrm{Ra}=10^{3}$, whereas for $\mathrm{Ra}=10^{5}$, it is $61 \%$. Phase deviation affects the flow field and rise of phase deviation results to enhance the average Nusselt number, this augmentation for $\theta=0$ to $\pi / 2$ is more than $\theta=\pi / 2$ to $\pi$ (Tables $3-5$ ). 

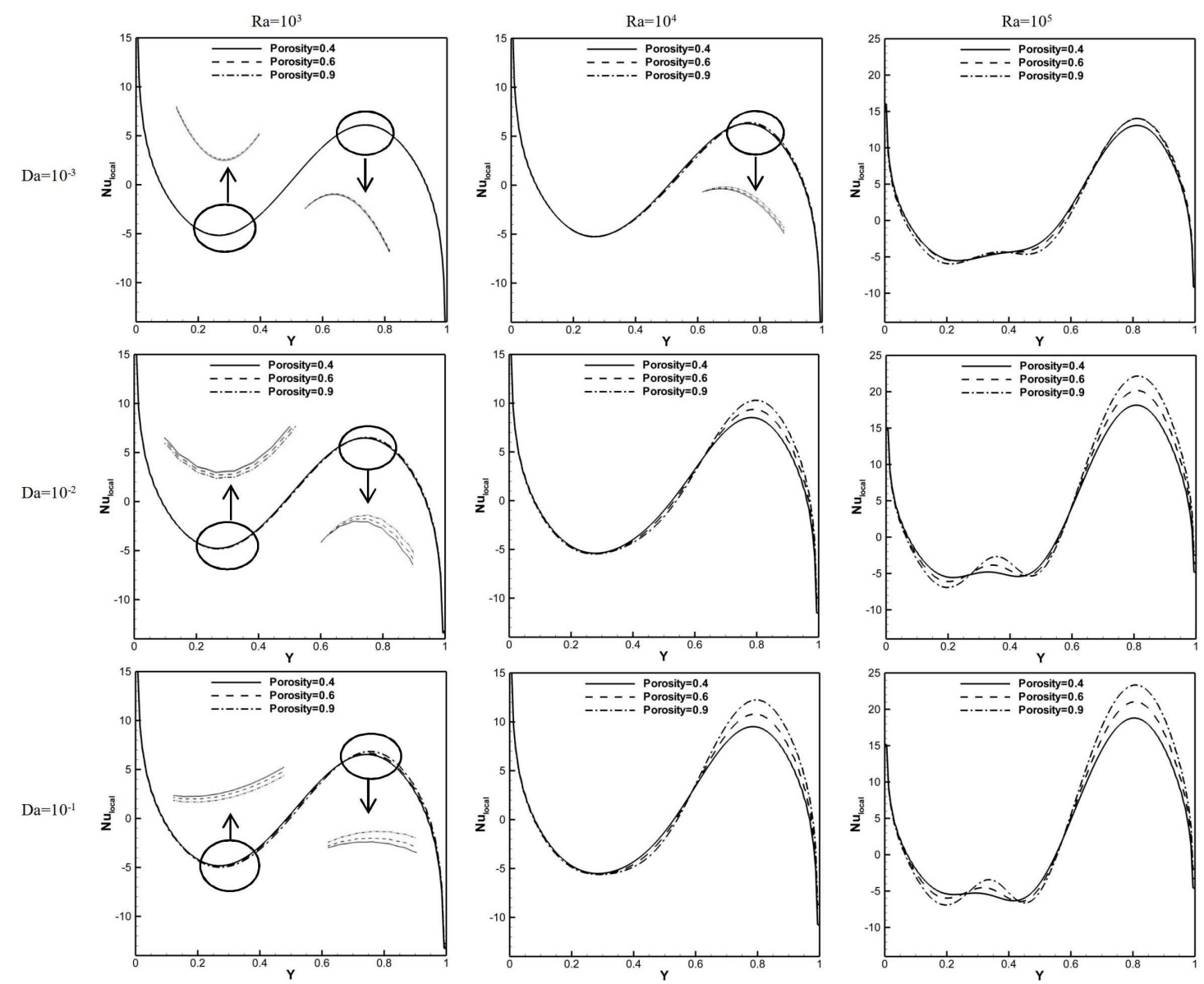

Figure 12: Variation of local Nusselt number on the right wall for various Darcy and Rayleigh numbers for multiple porosities, $\theta=0, \varnothing=0$.

Temperature contours and streamlines for the various volumetric fraction of the nanoparticles at $\mathrm{Ra}=10^{4}, \varepsilon=0.4, \mathrm{Da}=0.01$, and $\theta=0$ are illustrated in Figs. 13 and 14, which show the effect of nanoparticles on heat transfer and flow field. As it is displayed in Fig. 13, by adding the nanoparticles, the gradient of the boundary layer increases, also the isotherms of nanofluid traverse more than base fluid which resulted to augment the heat transfer rate. Fig. 14 shows that nanoparticles expand the streamlines more than the pure fluid, which results into an increase of the maximum value of streamlines and heat transfer rate.

Figs. 15 and 16 indicate the local Nusselt number on the left and right walls at $\mathrm{Ra}=10^{4}$, $\varepsilon=0.4, \mathrm{Da}=0.01$, and $\theta=0$ for different volume fractions on nanoparticles, respectively. The local Nusselt number on the left wall increases by increasing volume fraction at the bottom of the cavity, but this increase is lesser in the $y$-direction and finally the local Nusselt number declines at the top of the enclosure. To understand this trend, see Fig. 13, 


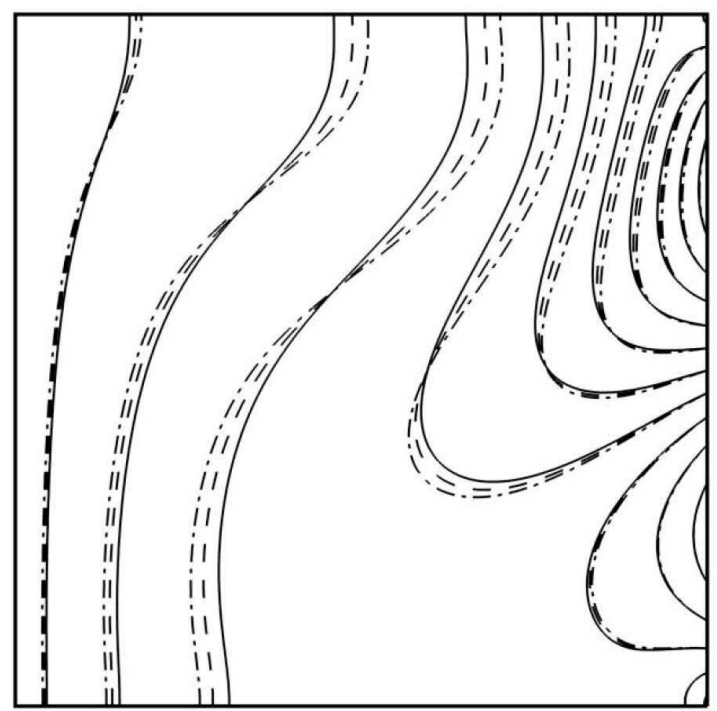

Figure 13: Temperature contours for various volumetric fractions of the nanoparticles for $\varnothing=0$ (solid), $\varnothing=2 \%$ (dashed), $\varnothing=4 \%$ (dashed-dot).

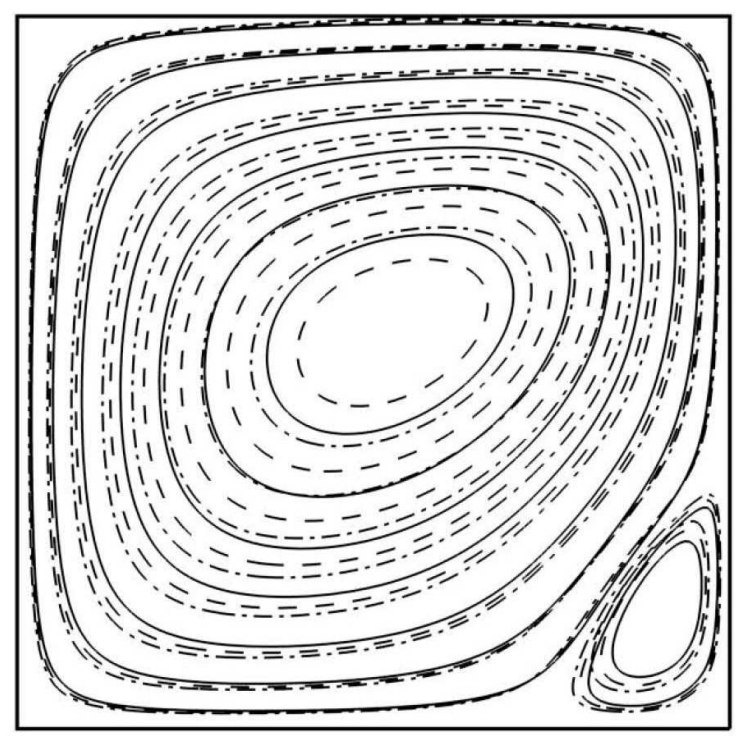

Figure 14: Streamlines for various volumetric fractions of the nanoparticles for $\varnothing=0$ (solid), $\varnothing=2 \%$ (dashed), $\varnothing=4 \%$ (dashed-dot).

that shows the boundary layer gradient increase by adding the nanoparticles for $Y<$ 0.5 , while for $Y>0.5$, the boundary layer gradient decreases. As the isotherms do not change significantly on the right wall (see Fig. 13) the local Nusselt number doesn't vary significantly, just at $Y=0.8$ where the quantity gets the maximum value. 


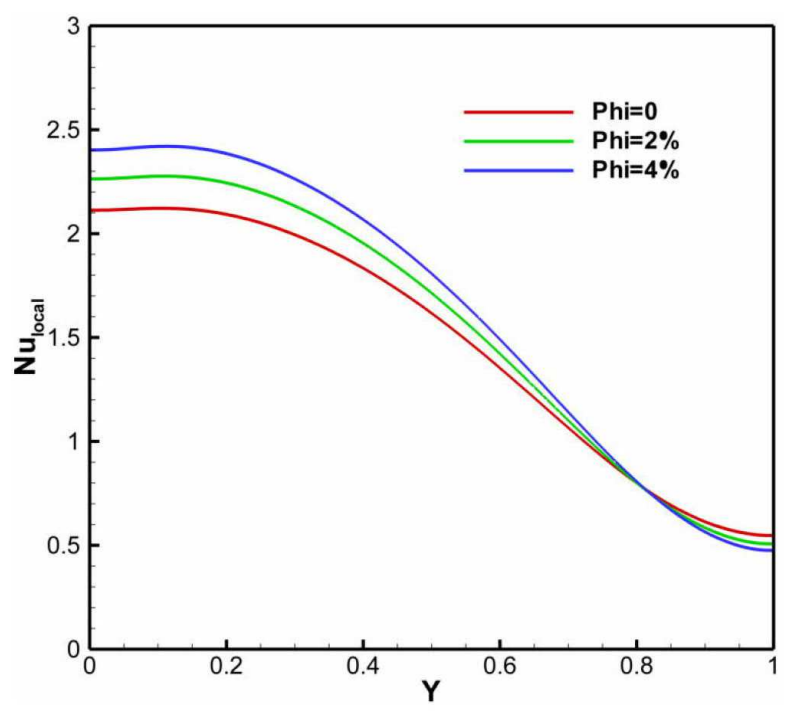

Figure 15: Comparison of the local Nusselt number on the left wall of the cavity for various volumetric fraction of the nanoparticles, $\mathrm{Ra}=10^{4}, \varepsilon=0.4, \mathrm{Da}=0.01$ and $\theta=0$.

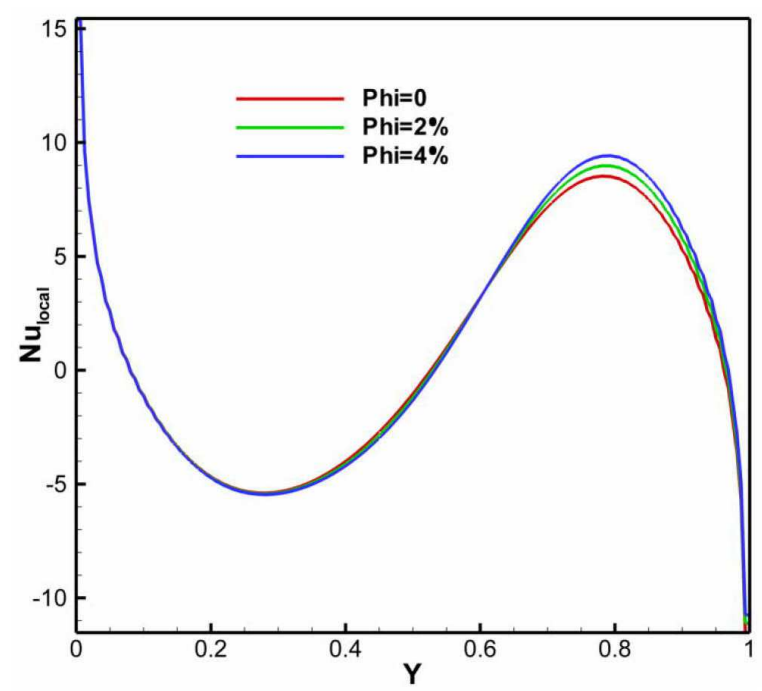

Figure 16: Comparison of the local Nusselt number on the right wall of the cavity for the various volumetric fraction of the nanoparticles, $\mathrm{Ra}=10^{4}, \varepsilon=0.4, \mathrm{Da}=0.01$ and $\theta=0$.

Figs. 17-19 indicate the local Nusselt number on the right wall for $\varepsilon=0.4, \varepsilon=0.6$, and $\varepsilon=0.9$, respectively. It is demonstrated that the maximum Nusselt number at the right wall decreases by augmentation of the phase deviation. Also the position of the peak falls down in $Y$-direction. Changing the Darcy number and porosity does not affect the local Nusselt number much, for all cases, and the value of the peaks varies smoothly. How- 

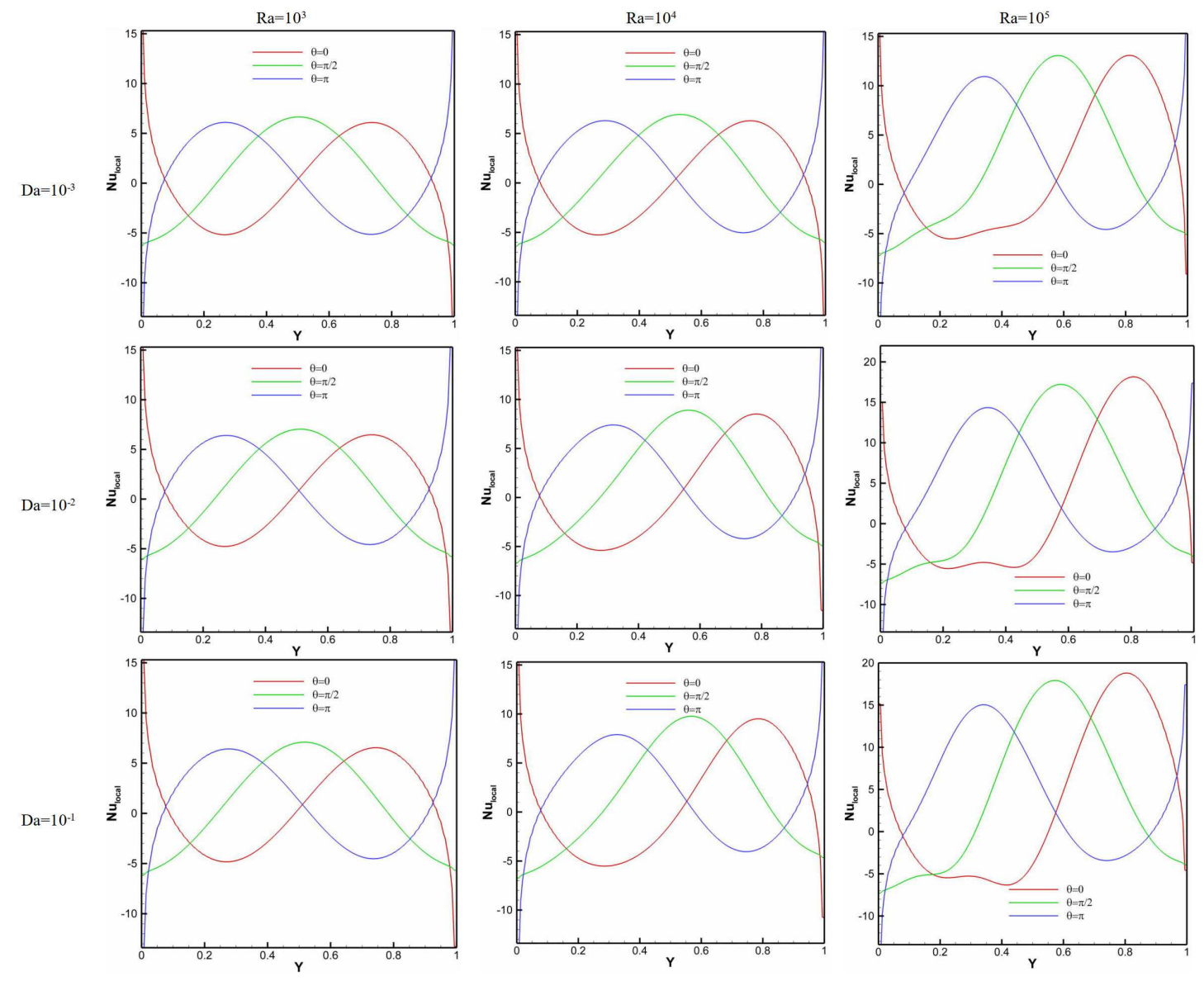

Figure 17: Variation of the local Nusselt number for the right wall at $\varepsilon=0.4$.

ever, the variation of Rayleigh number alters the local Nusselt number remarkably, as the maximum of local Nusselt number increases around 100\% for all cases, by amplification of Rayleigh number from $10^{4}$ to $10^{5}$, so the buoyancy force has the most significant effect on the heat transfer rate.

\section{Conclusion}

In this work, the double MRT-LBM is utilized to investigate the natural convection of a nanofluid in a porous cavity with a complex boundary conditions. The effect of various parameters on the flow pattern is considered and, based on the present results, the following conclusions are drawn:

- The double MRT-LBM method is adequate to solve complex nanoflows in porous media with heat transfer. 

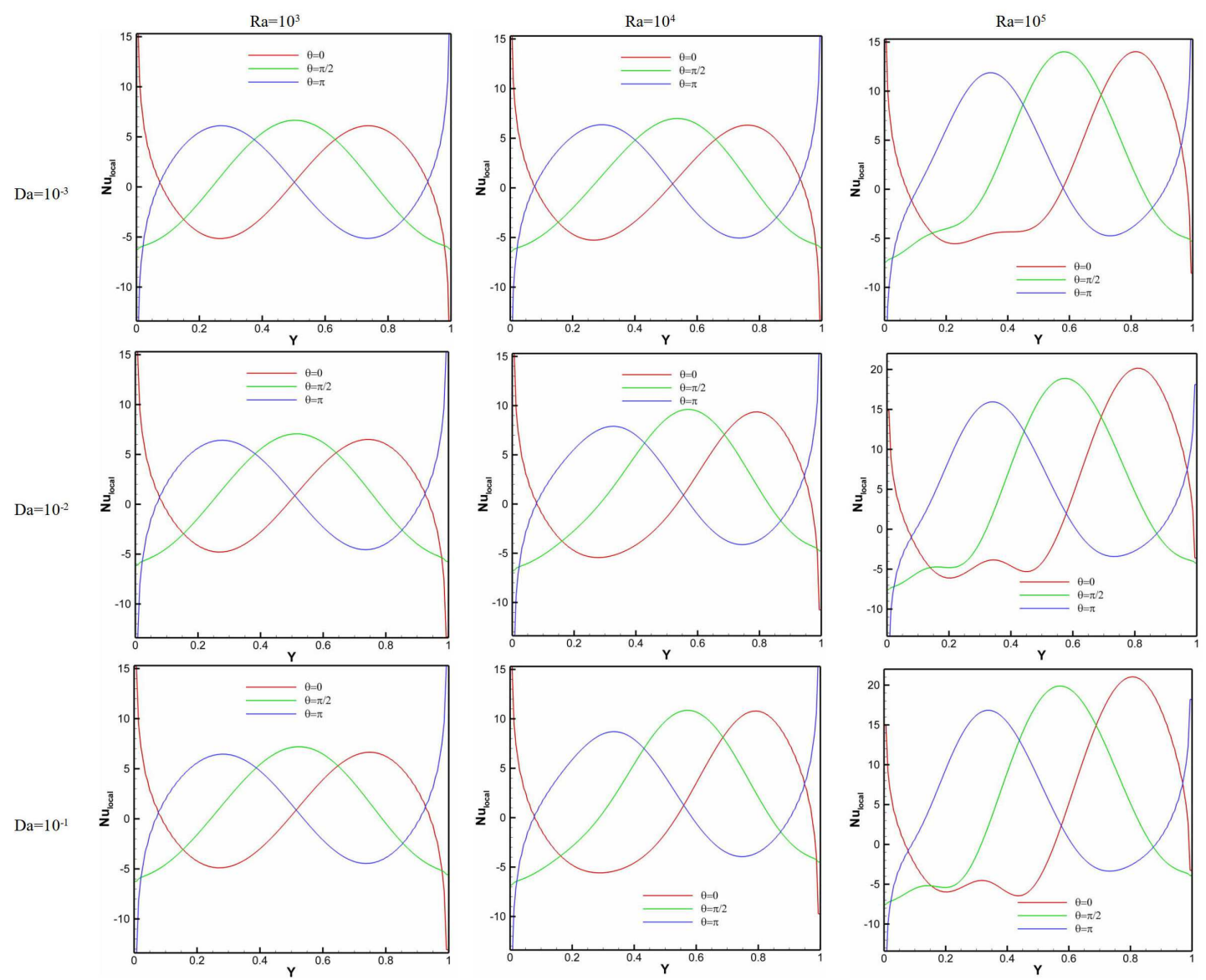

Figure 18: Variation of the local Nusselt number for the right wall at $\varepsilon=0.6$.

- Porosity affects the flow and temperature fields, and heat transfer rate is enhanced by increasing the porosity and the value of this enhancement rises by Rayleigh number.

- Adding nanoparticles improves the thermal conductivity of the pure fluid, the Nusselt number increasing by $10 \%$ upon adding $4 \%$ cu nanoparticle.

- Changing the temperature distribution of the right wall altered the buoyancy force, as the heat transfer rate increases by phase deviation and maximum growth of average Nusselt number is $18 \%$ when the phase deviation rises to $\pi$, for $\mathrm{Ra}=10^{5}$.

- Among the set of parameters considered here, the most intense effect on heat transfer rate is observed by changing the Rayleigh number, with a maximum enhancement in average Nusselt number of $344 \%$ in going from $\mathrm{Ra}=10^{3}$ to $\mathrm{Ra}=10^{5}$. 

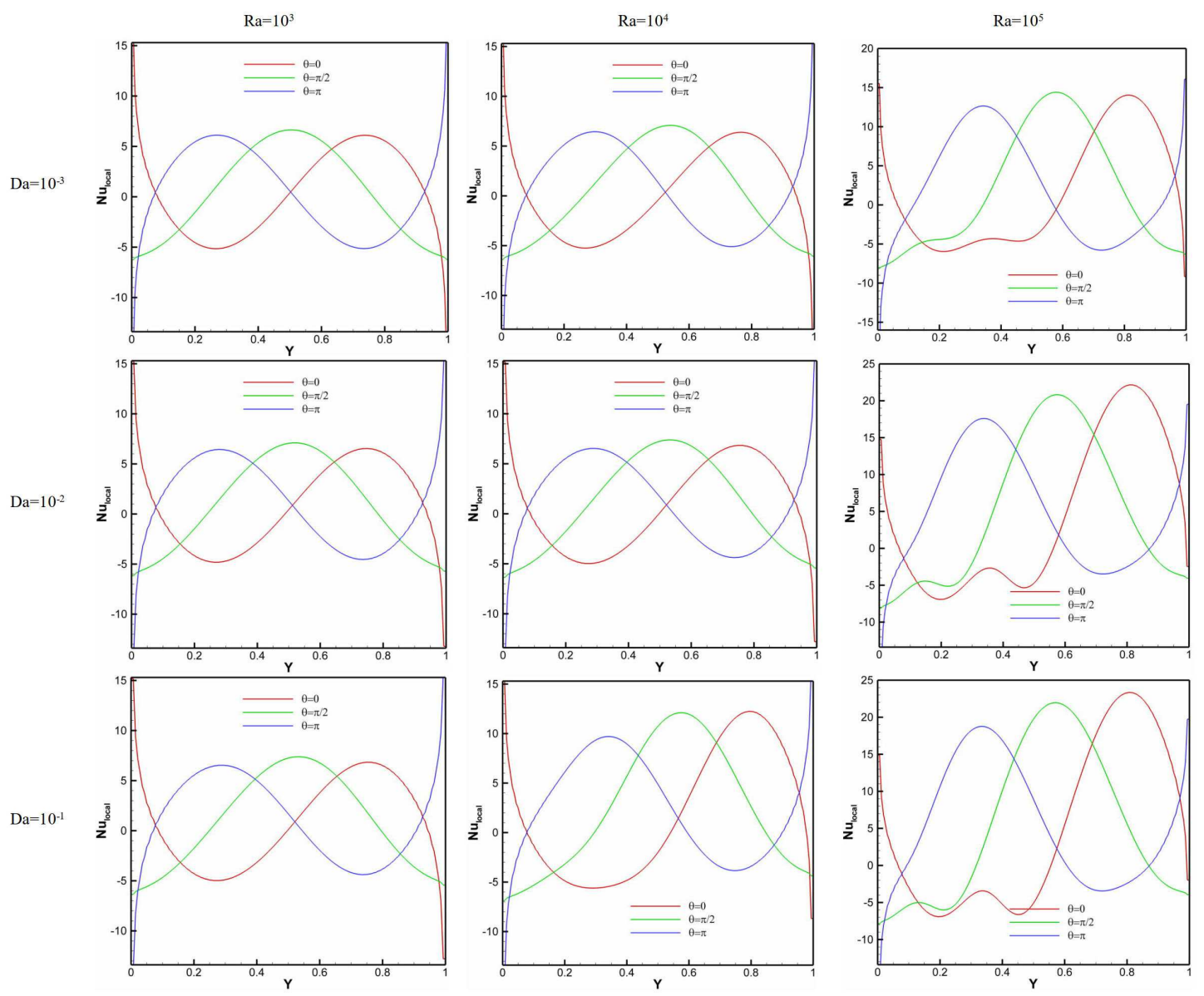

Figure 19: Variation of the local Nusselt number for the right wall at $\varepsilon=0.9$.

\section{Acknowledgments}

S. Succi wishes to acknowledge funding from the European Research Council under the Horizon 2020 Programme Grant Agreement n. 739964 ("COPMAT").

\section{References}

[1] H. Sajjadi, M. Salmanzadeh, G. Ahmadi, S. Jafari, Turbulent Indoor Airflow Simulation Using Hybrid LES/RANS Model Utilizing Lattice Boltzmann Method, Computers and fluids, 150 (2017) 66-73.

[2] H. Sajjadi, M. Salmanzadeh, G. Ahmadi, S. Jafari, Combination of Lattice Boltzmann Method and RANS Approach for Simulation of Turbulent Flows and Particle Transport and Deposition, Particuology, 30 (2017) 62-72. 
[3] H. Sajjadi, M. Salmanzadeh, G. Ahmadi, S. Jafari, LES and RANS Model Based on LBM for Simulation of Indoor Airflow and Particle Dispersion and Deposition, Building and Environment, 102 (2016) 1-12.

[4] H. Sajjadi, M. Gorji, GH.R. Kefayati, D.D.Ganji, Lattice Boltzmann simulation of turbulent natural convection in tall enclosures using $\mathrm{Cu}$ /water nanofluid, Numerical Heat Transfer Part A, 62 (2012) 512-530.

[5] R. Benzi, S. Succi, M. Vergassola, The lattice Boltzmann equation: theory and applications, Physics Reports, 222 (1992) 145-197.

[6] H Sajjadi, GHR Kefayati, MHD turbulent and laminar natural convection in a square cavity utilizing lattice Boltzmann method, Heat Transfer-Asian Research, 45 (2016) 795-814.

[7] H. Sajjadi, M. Gorji, GH.R. Kefayati, D.D. Ganji, M. Shayannia, Simulation of natural convection flow in an inclined open cavity using Lattice Boltzmann Method, World Academy of Science, Engineering and Technology, 55 (2011) 625-271.

[8] S. Succi, Lattice Boltzmann 2038, EPL, 109 (2015) 50001.

[9] F. J. Higuera, S. Succi, R. Benzi, Lattice Gas Dynamics with Enhanced Collisions, Europhysics Letters, 9 (1989) 345.

[10] R. Mohebbi, M. M. Rashidi, M. Izadi, N. A. C. Sidik, H. W. Xiane, Forced Convection of Nanofluids in an Extended Surfaces Channel using Lattice Boltzmann Method, International Journal of Heat and Mass Transfer, 117 (2018) 1291-1303.

[11] A. Jalali, A. Amiri Delouei, M. Khorashadizadeh, A.M. Golmohammadi, S. Karimnejad, Mesoscopic Simulation of Forced Convective Heat Transfer of Carreau-Yasuda Fluid Flow Over an Inclined Square: Temperature-dependent Viscosity, Journal of Applied and Computational Mechanics, 6 (2020), 307-319.

[12] R. Mohebbi, M. Izadi, H. Sajjadi, A. Amiri Delouei, M.A. Sheremet, Examining of nanofluid natural convection heat transfer in a $\Gamma$-shaped enclosure including a rectangular hot obstacle using the lattice Boltzmann method, Physica A: Statistical Mechanics and its Applications, 526 (2019), 120831.

[13] H. Sajjadi, A. Amiri Delouei, M. Sheikholeslami, M. Atashafrooz, S. Succi, Simulation of three dimensional MHD natural convection using double MRT Lattice Boltzmann method, Physica A: Statistical Mechanics and its Applications, 515 (2019), 474-496.

[14] H. Sajjadi, A. Amiri Delouei, M. Izadi, R. Mohebbi, Investigation of MHD natural convection in a porous media by double MRT lattice Boltzmann method utilizing MWCNTFe3O4/water hybrid nanofluid, International Journal of Heat and Mass Transfer, 132 (2019) 1087-1104.

[15] S. Succi, M. Vergassola, R. Benzi, Lattice Boltzmann scheme for two-dimensional magnetohydrodynamics, Physical Review A, 43 (1991) 4521.

[16] S. Chen, H. Chen, D. Martnez, W. Matthaeus, Lattice Boltzmann model for simulation of magnetohydrodynamics, Physics Review Letter, 67 (1991) 3776-3779.

[17] A. Amiri Delouei, M. Nazari, M. H. Kayhani, S. Succi, Immersed Boundary - Thermal Lattice Boltzmann Methods for Non-Newtonian Flows over a Heated Cylinder: A Comparative Study, Communications in Computational Physics, 18 (2015), 489-515.

[18] A. Amiri Delouei, M. Nazari, M. H. Kayhani, S. Succi, Non-Newtonian unconned ow and heat transfer over a heated cylinder using the direct-forcing immersed boundary-thermal lattice Boltzmann method, Physical Review E, 89 (2014), 053312.

[19] A. Amiri Delouei, M. Nazari, M. H. Kayhani, S.K. Kang, S. Succi, Non-Newtonian Particulate Flow Simulation: A Direct-Forcing Immersed Boundary-Lattice Boltzmann Approach, Physica A: Statistical Mechanics and its Applications, 447, 1-20, 2016. 
[20] A. Amiri Delouei, M. Nazari, M. H. Kayhani, G. Ahmadi, A Non-Newtonian Direct Numerical Study for Stationary and Moving Objects with Various Shapes: An Immersed Boundary -Lattice Boltzmann Approach, Journal of Aerosol Science, 93 (2016), 45-62.

[21] A. Amiri Delouei, M. Nazari, M. H. Kayhani, G. Ahmadi, Direct-Forcing Immersed Boundary-Non-Newtonian Lattice Boltzmann Method for Transient Non-Isothermal Sedimentations, Journal of Aerosol Science, 104 (2017), 106-122.

[22] B. Afra, M. Nazari, M. H. Kayhani, A. Amiri Delouei, G. Ahmadi, An immersed boundarylattice Boltzmann method combined with a robust lattice spring model for solving owstructure interaction problems, Applied Mathematical Modelling, 55 (2018), 502-521.

[23] S. Karimnejad, A. Amiri Delouei, M. Nazari, M.M. Shahmardan, A.A. Mohamad, Sedimentation of elliptical particles using Immersed Boundary - Lattice Boltzmann Method: A complementary repulsive force model, Journal of Molecular Liquids, 262 (2018) 180-193.

[24] S. Karimnejad, A. Amiri Delouei, M. Nazari, M. Shahmardan, M. Rashidi, and S. Wongwises, Immersed boundary-thermal lattice Boltzmann method for the moving simulation of nonisothermal elliptical particles, Journal of Thermal Analysis and Calorimetry, 138 (2019) 40034017.

[25] P. Prestininzi, A. Montessori, M. La Rocca, S. Succi, Reassessing the single relaxation time lattice Boltzmann method for the simulation of Darcy's flows, International Journal of Modern Physics C, 27 (2016) 1650037.

[26] A. d'Orazio, S. Succi, C. Arrighetti, Lattice Boltzmann simulation of open flows with heat transfer, Physics of fluids, 15 (2003) 2778-2781.

[27] P. Lallemand, L. Luo, Theory of the lattice Boltzmann method: dispersion, dissipation, isotropy, Galilean invariance, and stability, Physical Review E, 61 (2000) 6546-6562.

[28] I. Ginzburg, Equilibrium-type and link-type lattice Boltzmann models for generic advection and anisotropic-dispersion equation, Advances in Water Resources, 28 (2005) 1171-1195.

[29] S. Chikatamarla, S. Ansumali, I. Karlin, Entropic lattice Boltzmann models for hydrodynamics in three dimensions, Physical Review Letter, 97 (2006) 010201.

[30] L. Luo, W. Liao, X. Chen, Y. Peng, W. Zhang, Numerics of the lattice Boltzmann method: effects of collision models on the lattice Boltzmann simulations, Physical Review E, 83 (2011) 056710.

[31] H. Sajjadi, A. Amiri Delouei, M. Atashafrooz, M. Sheikholeslami, Double MRT Lattice Boltzmann simulation of 3-D MHD natural convection in a cubic cavity with sinusoidal temperature distribution utilizing nanofluid, International Journal of Heat and Mass Transfer, 126 (2018) 489-503.

[32] H. R. Ashorynejad, A. Zarghami, Magnetohydrodynamics flow and heat transfer of Cuwater nanofluid through a partially porous wavy channel, International Journal of Heat and Mass Transfer 119 (2018) 247-258.

[33] A. Abouei Mehrizi, M. Farhadi, S. Shayamehr, Natural convection flow of Cu-Water nanofluid in horizontal cylindrical annuli with inner triangular cylinder using lattice Boltzmann method, International Communications in Heat and Mass Transfer, 44 (2013) 147-156.

[34] H. Sajjadi, M. Beigzadeh Abbassi, GH.R. Kefayati, Lattice Boltzmann simulation of turbulent natural convection in a square cavity using $\mathrm{Cu}$ /water nanofluid, Journal of Mechanical Science and Technology, 27 (2013) 2341-2349.

[35] H. Sajjadi, M. Gorji, GH.R. Kefayati, D. D. Ganji, Lattice Boltzmann simulation of natural convection in an inclined heated cavity partially using $\mathrm{Cu}$ /water nanofluid, International Journal of Fluid Mechanical Research, 39 (2012) 348-372.

[36] A. A. Mehrizi, K. Sedighi, M. Farhadi, M. Sheikholeslami, Lattice Boltzmann simulation of 
natural convection heat transfer in an elliptical-triangular annulus, International Communications in Heat and Mass Transfer, 48 (2013) 164-177.

[37] G.H.R.Kefayati, Mixed convection of non-Newtonian nanofluid in an enclosure using Buongiorno's mathematical model, International Journal of Heat and Mass Transfer, 108 (2017) 1481-1500.

[38] Gh. Hoghoughi, M. Izadi, H. F. Oztop, N. Abu-Hamdeh, Effect of geometrical parameters on natural convection in a porous undulant-wall enclosure saturated by a nanofluid using Buongiorno's model, Journal of Molecular Liquids, 255 (2018) 148-159.

[39] M. Izadi, S. Sinaei, S. A. M. Mehryan, H. F. Oztop, N. Abu-Hamdeh, Natural convection of a nanofluid between two eccentric cylinders saturated by porous material: Buongiorno's two phase model, International Journal of Heat and Mass Transfer, 127 (2018) 67-75.

[40] M. Sheikholeslami, M. Gorji-Bandpy, D.D. Ganji, S. Soleimani, Natural convection heat transfer in a cavity with sinusoidal wall filled with $\mathrm{CuO}$-water nanofluid with the presence of magnetic field, Journal of the Taiwan Institute of Chemical Engineers 45 (2014) 40-49.

[41] W. Tang, M. Hatami, J. Zhou, D. Jing, Natural convection heat transfer in a nanofluid-filled cavity with double sinusoidal wavy walls of various phase deviations, International Journal of Heat and Mass Transfer 115 (2017) 430-440.

[42] M. Sheikholeslami, R. Ellahi, Three dimensional mesoscopic simulation of magnetic field effect on natural convection of nanofluid, International Journal of Heat and Mass Transfer, 89 (2015) 799-808.

[43] A.I. Alsabery, A.J. Chamkha, S.H. Hussain, H. Saleh, I. Hashim, Heatline visualization of conjugate natural convection in a square cavity filled with nanofluid with sinusoidal temperature variations on both horizontal walls, International Journal of Heat and Mass Transfer 100 (2016) 835-850.

[44] R. Mohebbi, M. Izadi, A. A. Delouei, H. Sajjadi, Effect of MWCNT-Fe3O4/water hybrid nanofluid on the thermal performance of ribbed channel with apart sections of heating and cooling, Journal of Thermal Analysis and Calorimetry, 135 (2019) 3029-3042.

[45] M. Qin, R. Belarbi, A. Ait-Mokhtar, L. Nilsson, Coupled heat and moisture transfer in multilayer building materials, Construction and Building Material, 23 (2009) 967-975.

[46] W. Wang, B. Laumert, H. Xu, T. Strand, Conjugate heat transfer analysis of an impinging receiver design for a dish-Brayton system, Solar Energy, 119 (2015)298-309.

[47] S. Chen, W. Gong, Y. Yan, Conjugate natural convection heat transfer in an open-ended square cavity partially filled with porous media, International Journal of Heat and Mass Transfer, 124 (2018) 368-380.

[48] M. S. Astanina, M. A. Sheremet, H. F. Oztop, N. Abu-Hamdeh, Mixed convection of Al2O3water nanofluid in a lid-driven cavity having two porous layers, International Journal of Heat and Mass Transfer, 118 (2018) 527-537.

[49] R. Ul Haq, F. Ahmed Soomro, T. Mekkaoui, Q. M. Al-Mdallal, MHD natural convection flow enclosure in a corrugated cavity filled with a porous medium, International Journal of Heat and Mass Transfer, 121 (2018) 1168-1178.

[50] S. Succi, E. Foti, F. Higuera, Three-dimensional flows in complex geometries with the lattice Boltzmann method, Europhysics Letters, 10 (1989) 433.

[51] T. Zhao, H. Zhao, Z. Ning, X. Li, Q. Wang, Permeability prediction of numerical reconstructed multiscale tight porous media using the representative elementary volume scale lattice Boltzmann method, International Journal of Heat and Mass Transfer, 118 (2018) 368377.

[52] Q. Liu, Y. L. He, Q. Li, W. Q. Tao, A multiple-relaxation-time lattice Boltzmann model for 
convection heat transfer in porous media, International Journal of Heat and Mass Transfer, 73 (2014) 761-775.

[53] G.H. Tang, W.Q. Tao, Y.L. He, Gas slippage effect on microscale porous flow using the lattice Boltzmann method, Physical Review E, 72 (2005) 056301.

[54] Q. Kang, D. Zhang, S. Chen, Unified lattice Boltzmann method for flow in multiscale porous media, Physical Review E, 66 (2002) 056307.

[55] Z. Guo, T.S. Zhao, Lattice Boltzmann model for incompressible flows through porous media, Physical Review E, 66 (2002) 036304.

[56] G.R. Kefayati, Simulation of natural convection and entropy generation of non-Newtonian nanofluid in a porous cavity using Buongiorno's mathematical model, International Journal of Heat and Mass Transfer, 112 (2017) 709-744.

[57] H. R. Ashorynejad, B. Hoseinpour, Investigation of different nanofluids effect on entropy generation on natural convection in a porous cavity, European Journal of Mechanics B/Fluids, 62 (2017) 86-93.

[58] K. Khanafer, K. Vafai, M. Lightstone, Buoyancy-driven heat transfer enhancement in a twodimensional enclosure utilizing nanofluids, International Journal of Heat and Mass Transfer, 46 (2003) 3639-3653.

[59] P. Nithiarasu, K. N. Seetharamu, and T. Sundararajan, Natural Convection Heat Transfer in a Fluid Saturated Variable Porosity Medium, International Journal of Heat and Mass Transfer, 40, (1997) 3955-3967.

[60] Z. Guo, T.S. Zhao, A lattice Boltzmann model for convection heat transfer in porous media, Numerical Heat Transfer Part B, 47 (2005) 157-177. 